\title{
The Pseudomonas aeruginosa antimetabolite L-2-amino-4- methoxy-trans-3-butenoic acid (AMB) is made from glutamate and two alanine residues via a thiotemplate-linked tripeptide precursor
}

\author{
Nelson Rojas Murcia ${ }^{1 \neq}$, Xiaoyun Lee ${ }^{1 \neq}$, Patrice Waridel ${ }^{2}$, Alessandro Maspoli ${ }^{1}$, Heidi J. Imker ${ }^{3 \dagger}$, \\ Tiancong Chai ${ }^{1}$, Christopher T. Walsh ${ }^{3}$ and Cornelia Reimmann ${ }^{1}$ *
}

${ }^{1}$ Department of Fundamental Microbiology, University of Lausanne, Lausanne, Switzerland

2 Protein Analysis Facility, University of Lausanne, Lausanne, Switzerland

${ }^{3}$ Department of Biological Chemistry and Molecular Pharmacology, Harvard Medical School, Boston, MA, USA

\section{Edited by:}

Paolo Visca, University Roma Tre, Italy

\section{Reviewed by:}

Pierre Cornelis, Vrije Universiteit Brussel, Belgium

Jeremy George Owen, The

Rockefeller University, USA

\section{*Correspondence:}

Cornelia Reimmann, Department of Fundamental Microbiology, University of Lausanne, Biophore Building,

Quartier UNIL-Sorge,

CH-1015 Lausanne, Switzerland

e-mail:cornelia.reimmann@unil.ch

${ }^{\dagger}$ Present address:

Heidi J. Imker, Research Data Service,

University of lllinois at

Urbana-Champaign, Urbana, IL, USA

FThese authors have contributed equally to this work.
The Pseudomonas aeruginosa toxin L-2-amino-4-methoxy-trans-3-butenoic acid (AMB) is a non-proteinogenic amino acid which is toxic for prokaryotes and eukaryotes. Production of $A M B$ requires a five-gene cluster encoding a putative LysE-type transporter ( $A m b A$ ), two non-ribosomal peptide synthetases (AmbB and AmbE), and two iron(II)/ $\alpha$-ketoglutaratedependent oxygenases ( $\mathrm{AmbC}$ and $\mathrm{AmbD}$ ). Bioinformatics analysis predicts one thiolation (T) domain for AmbB and two $T$ domains ( $T 1$ and T2) for $A m b E$, suggesting that $A M B$ is generated by a processing step from a precursor tripeptide assembled on a thiotemplate. Using a combination of ATP-PPi exchange assays, aminoacylation assays, and mass spectrometry-based analysis of enzyme-bound substrates and pathway intermediates, the AmbB substrate was identified to be L-alanine (L-Ala), while the T1 and T2 domains of AmbE were loaded with L-glutamate (L-Glu) and L-Ala, respectively. Loading of L-Ala at T2 of $A m b E$ occurred only in the presence of $A m b B$, indicative of a trans loading mechanism. In vitro assays performed with $\mathrm{AmbB}$ and $\mathrm{AmbE}$ revealed the dipeptide L-Glu-L-Ala at T1 and the tripeptide L-Ala-L-Glu-L-Ala attached at T2. When AmbC and AmbD were included in the assay, these peptides were no longer detected. Instead, an L-Ala-AMB-L-Ala tripeptide was found at T2. These data are in agreement with a biosynthetic model in which L-Glu is converted into $\mathrm{AMB}$ by the action of $\mathrm{AmbC}, \mathrm{AmbD}$, and tailoring domains of $\mathrm{AmbE}$. The importance of the flanking L-Ala residues in the precursor tripeptide is discussed.

Keywords: Pseudomonas, toxin, oxyvinylglycine, secondary metabolite, thiotemplate

\section{INTRODUCTION}

Pseudomonas aeruginosa is an opportunistic pathogen often affecting patients who suffer from compromised antimicrobial barriers, as for instance the genetic disease cystic fibrosis (Lyczak etal., 2002). One of the many toxins that this bacterium produces is L-2-amino-4-methoxy-trans-3-butenoic acid (AMB), a non-proteinogenic amino acid belonging to a small group of natural compounds known as oxyvinylglycines (Berkowitz et al., 2006). Other members of this group are aminoethoxyvinylglycine (AVG), dimethyliminooxyvinylglycine, and guanidinooxyvinylglycine from Streptomyces spp. (Pruess et al., 1974; Hirata et al., 1993), rhizobitoxin made by Bradyrhizobium japonicum and $P$. andropogonis (Owens etal., 1972; Mitchell et al., 1986), as well as the recently identified 4 -formylaminooxyvinylglycine (FVG) isolated from P. fluorescens WH6 (McPhail et al., 2010). Oxyvinylglycines irreversibly inhibit pyridoxal phosphate (PLP)-dependent enzymes and thus have multiple targets in bacteria, animals, and plants (Berkowitz et al., 2006). A prominent plant target is the ethylene biosynthesis enzyme ACC synthase, which is inhibited by AVG. Commercially available under the name of Retain ${ }^{\circledR}$, AVG is widely used for the regulation of fruit set in orchard crops.
Another example with potential for an agricultural application is FVG. This oxyvinylglycine is a natural herbicide which blocks the germination of a large variety of grassy weed species (Banowetz et al., 2008).

Pyridoxal phosphate-dependent enzymes are also targeted by AMB. Isolated originally as a growth inhibitor of Bacillus subtilis (Scannell et al., 1972) and Escherichia coli (Sahm etal., 1973), AMB was shown to inhibit apartate aminotransferase in pigs (Rando, 1974; Rando etal., 1976) and rat hepatocytes (Smith and Freeland, 1981; Cornell et al., 1984), tryptophane synthase in E. coli (Miles, 1975), $\delta$-aminolevulinic acid synthetase in rats (Dashman and Kamm, 1979), and serine hydroxylmethyl transferase in Walker carcinoma (Tisdale, 1981). Reversible inhibition of L-methionine tRNA aminoacylation was also reported, suggesting that $\mathrm{AMB}$ can function as a methionine antimetabolite (Matoo et al., 1979). We recently evaluated the importance of $\mathrm{AMB}$ as a $P$. aeruginosa virulence factor using an Acanthamoeba castellanii cell model (Lee et al., 2012). Although $\mathrm{AMB}$ was found to inhibit growth and to induce cyst formation, the effective concentrations were rather high, making a strong contribution of $\mathrm{AMB}$ to the virulence of $P$. aeruginosa 
unlikely. AMB may be more important during interactions of $P$. aeruginosa with other microbes and it is interesting to note in this respect that $\mathrm{AMB}$ can inhibit the growth of important plant and animal pathogens such as Erwinia amylovora (Lee etal., 2013a) and Staphylococcus aureus (our unpublished observation).

Transposon mutagenesis and reverse genetics have previously led to the identification of the $P$. aeruginosa ambABCDE gene cluster which comprises two transcriptional units (Lee et al., 2010, 2013a; Figure 1). Transfer of this cluster to strains devoid of $a m b$ genes, such as $P$. aeruginosa PA7, or $P$. fluorescens CHA0, rendered them capable of synthesizing AMB (Lee et al., 2010, 2013a), demonstrating that these genes are both essential and sufficient for AMB production. Bioinformatics analyses indicate that the first transcriptional unit, $a m b A$, encodes a putative LysE-type transporter and may thus account for AMB secretion. The second transcriptional unit specifies four proteins predicted to be involved in AMB biosynthesis. Two of these, AmbB and AmbE, present the typical modular structure of non-ribosomal peptide synthetases (NRPSs; Figure 1). The gene products of $a m b C$ and $a m b D$ are predicted to belong to the family of iron(II)/ $\alpha$ ketoglutarate-dependent oxygenases. Most members of this family catalyze hydroxylation of a substrate coupled to the oxidative decarboxylation of an $\alpha$-ketoglutarate cofactor using iron (II) as the redox catalyst. However, other members also catalyze reactions such as oxidative desaturation or cyclization (Hausinger, 2004).

Based on the observation that the Amb assembly line contains three thiolation domains, (i.e., attachment points for amino acid precursors, see Figure 1), we postulate that AMB biosynthesis proceeds via a precursor tripeptide. Using in vitro methods and analysis of enzyme-attached substrates and pathway intermediates by mass spectrometry (MS), we identified the building blocks of AMB biosynthesis and we present a model of how the AMB precursor tripeptide may be assembled.

\section{MATERIALS AND METHODS} BACTERIAL STRAINS, PLASMIDS, AND CULTURE CONDITIONS

Strains and plasmids used in this study are listed in Table 1. Bacteria were routinely cultivated at $37^{\circ} \mathrm{C}$ on nutrient agar and in nutrient yeast broth (Stanisich and Holloway, 1972). To facilite uptake of heterologous DNA during conjugation and transformation, $P$. aeruginosa was grown at $43^{\circ} \mathrm{C}$. When necessary, antibiotics were added to the media of $E$. coli at the following concentrations: ampicillin at $100 \mu \mathrm{g} \mathrm{ml}^{-1}$, chlorampheniol $(\mathrm{Cm})$ at $30 \mu \mathrm{g} \mathrm{ml}^{-1}$, kanamycin $(\mathrm{Km})$, and tetracycline (Tc) at $25 \mu \mathrm{g} \mathrm{ml}^{-1}$ each. For selection of Tc-resistant plasmids in P. aeruginosa, Tc was used at $125 \mu \mathrm{g} \mathrm{ml}{ }^{-1}$. Counterselection of E. coli donor cells during mutant construction occurred with $\mathrm{Cm}$ at $10 \mu \mathrm{g} \mathrm{ml}^{-1}$; mutant enrichment was performed with Tc at $20 \mu \mathrm{g} \mathrm{ml}^{-1}$ and carbenicillin $(\mathrm{Cb})$ at $2 \mathrm{mg} \mathrm{ml}^{-1}$. For protein purification, cultures were induced with isopropyl $\beta$-D-1-thiogalactopyranoside (IPTG) as detailed below.

\section{DNA MANIPULATIONS AND SEQUENCING}

DNA manipulations were done according to standard procedures (Sambrook and Russell, 2001). Plasmid DNA was prepared using Jetstar (Genomed GmbH) and QIAprep Spin Miniprep (Qiagen, Inc.) kits; DNA fragments were gel-purified with the Invisorb ${ }^{\circledR}$ fragment cleanUp kit from Invitek. Bacterial transformations were done by electroporation (Farinha and Kropinski, 1990). Constructs involving PCR techniques (for oligonucleotides see Table 2) were verified by commercial sequence analysis carried out at GATC Biotech.

\section{CONSTRUCTION OF OVEREXPRESSION PLASMIDS FOR PROTEIN PURIFICATION}

For overexpression of $a m b B$, the gene was PCR-amplified from chromosomal DNA of PAO1 using the primer pair XL009/XL010. The 3.8-kb PCR fragment was trimmed with NheI and EcoRI and cloned between the same sites in pET-28a. This generated

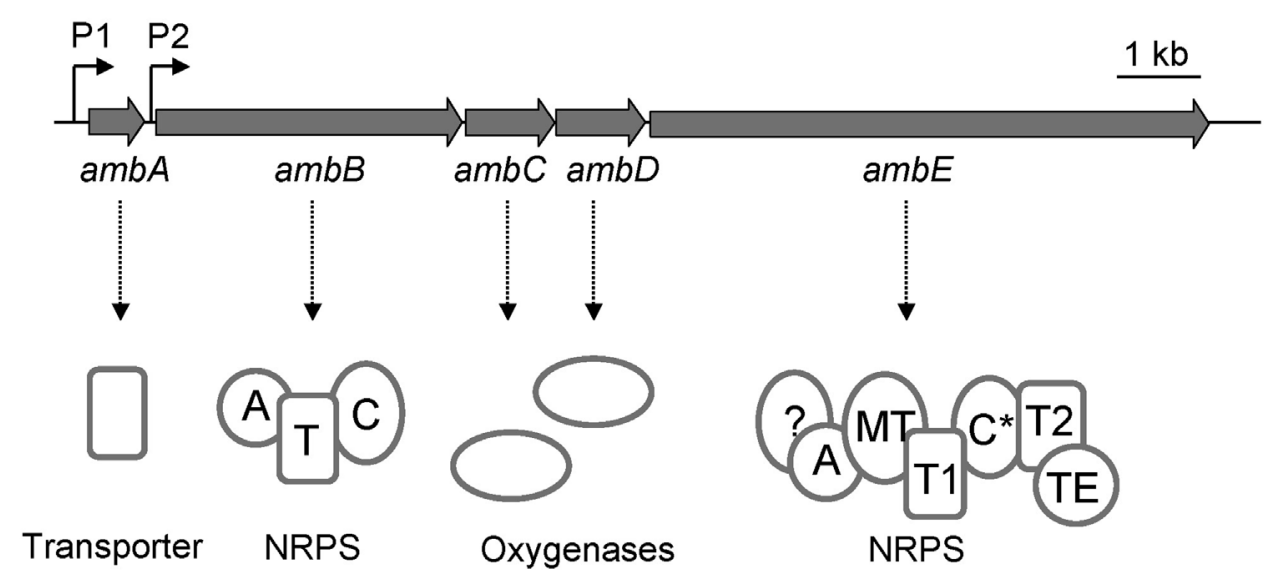

FIGURE 1 | Organization of the amb gene cluster in the Pseudomonas aeruginosa strain PAO1. The ambA gene encodes a putative LysE-type transmembrane protein potentially involved in AMB export, $a m b B$ and $a m b E$ code for non-ribosomal peptide synthetases (NRPS), and $a m b C$ and $a m b D$ specify two putative iron (II)/ $\alpha$-ketoglutarate-dependent oxygenases. The modular structures of $\mathrm{AmbB}$ and $\mathrm{AmbE}$ are shown with domains for adenylation (A), thiolation (T), condensation (C), methylation (MT), and thioester cleavage (TE). Note that AmbE may have an additional domain of unknown function at its $\mathrm{N}$-terminus and that the $\mathrm{C}$ domain (indicated as $\mathrm{C}^{*}$ ) is atypical (see text for details). 
Table 1 | Bacterial strains and plasmids.

\begin{tabular}{|c|c|c|}
\hline Name & Relevant characteristics & Reference/Source \\
\hline \multicolumn{3}{|c|}{ Escherichia coli strains } \\
\hline BL21(DE3) & $\mathrm{F}^{-}, \mathrm{ompT}, \mathrm{gal}, \mathrm{dcm}, \mathrm{lon}, h s d S_{B}\left(\mathrm{r}_{B}^{-} \mathrm{m}_{B}^{-}\right), \lambda(\mathrm{DE} 3)$ & Novagen \\
\hline BL21(DE3)/pLys & $\mathrm{F}^{-}$, ompT, gal, dcm, lon, $h s d S_{B}\left(\mathrm{r}_{\mathrm{B}}^{-} \mathrm{m}_{\mathrm{B}}^{-}\right), \lambda(\mathrm{DE} 3) / \mathrm{pLys} ; \mathrm{Cm}^{r}$ & Novagen \\
\hline $\mathrm{DH} 5 \alpha$ & recA1 endA1 hsdR17 deoR thi-1 supE44 gyrA96 relA1 $\Delta($ lacZYA-argF) U169 ( $\phi 80 \mathrm{~d} / a c Z \Delta M 15)$ & Sambrook and Russell (2001) \\
\hline $\mathrm{K} 12$ & Wild type & Tatum and Lederberg (1947) \\
\hline PAO1 & Wild type & ATCC 15692 \\
\hline PAO6932 & $a m b B_{T 2302 G}$ (specifying $A_{m b} B_{S 768 A}$ ) & This study \\
\hline PAO6934 & $a m b E_{T 3856 \mathrm{G}}$ (specifying $\mathrm{Amb}_{\mathrm{S} 1286 \mathrm{~A}}$ ) & This study \\
\hline PAO6935 & $a m b E_{T 5455 G, G 5457 \mathrm{~A}}$ (specifying $\mathrm{Amb}_{\mathrm{S} 1819 \mathrm{~A}}$ ) & This study \\
\hline pET-29Sfp & Expression plasmid for $\mathrm{Sfp}-\mathrm{His}_{6} ; \mathrm{Km}^{r}$ & Yin etal. (2006) \\
\hline pME497 & Mobilizing plasmid, $A p^{r}$ & Voisard et al. (1988) \\
\hline pME3087 & Suicide vector, ColE1 replicon; $T c^{r}$ & Voisard et al. (1988) \\
\hline pME9713 & pET-28a-based expression plasmid for $\mathrm{His}_{6}-\mathrm{AmbB} ; \mathrm{Km}^{\mathrm{r}}$ & This study \\
\hline pME9714 & pET-27b-based expression plasmid for AmbE-His $;{ }_{6} ; m^{r}$ & This study \\
\hline pME9717 & pET-27b-based expression plasmid for AmbD-His $6 ; \mathrm{Km}^{r}$ & This study \\
\hline pME9718 & pET-27b-based expression plasmid for AmbC-His $; \mathrm{Km}^{r}$ & This study \\
\hline pME10317 & pET-27b-based expression vector for AmbE $E_{S 1819 A}-H_{i s_{6}} ; \mathrm{Km}^{r}$ & This study \\
\hline pME10326 & $\begin{array}{l}\text { pME3087 derivative for generating a S768A mutation in the thiolation domain of AmbB (replacing } \\
\text { codon GGT against GGC) }\end{array}$ & This study \\
\hline pME10341 & $\begin{array}{l}\text { pME3087 derivative for generating a S1819A mutation in the second thiolation domain of AmbE } \\
\text { (replacing codon TCG against GCA) }\end{array}$ & This study \\
\hline
\end{tabular}

pME9713 in which the $a m b B$ gene is fused in-frame to six histidine codons at its $5^{\prime}$ end and expressed under the control of the T7 promoter. To construct pME10327 (for purification of $\mathrm{AmbB}_{\mathrm{S} 768 \mathrm{~A}}$ ), a 2.6-kb BamHI-EcoRI fragment with the thiolation site mutation was generated by overlap extension PCR from chromosomal DNA of PAO1 using the primer pairs XL202/XL203 and XL204/XL010. This fragment was then used to replace the corresponding fragment in pME9713.

For construction of the $a m b C$ expression plasmid pME9718, a 1.1-kb fragment was PCR-amplified from chromosomal DNA of PAO1 with primers XL036 and XL044, trimmed with NdeI and EcoRI, and cloned into pET-27b between the same sites. The $a m b D$ expression plasmid pME9717 was made in the same way, using primers XL034 and XL042 instead.
Plasmids for $a m b E$ expression were constructed as follows. The $a m b E$ gene was PCR-amplified from chromosomal DNA of PAO1 using the primer pair XL007/XL033. The resulting fragment of $6.4 \mathrm{~kb}$ was then cloned into pET-27b between the NdeI and NheI restriction sites. This produced pME9714 in which $a m b E$ is fused in-frame to six histidine codons at its $3^{\prime}$ end and expressed from the T7 promoter. Variants of pME9714 with mutations in the T1 domain (pME10337), the T2 domain (pME10317), and the TE domain (pME10328) were constructed by overlap extension PCR using the primer pairs XL032/XL206 + XL207/XL097 (for pME10337), XL032/XL094 + XL095/XL097 (for pME10317), and XL032/XL102 + XL101/XL097 (for pME10328), respectively. This generated 2.6-kb fragments which were trimmed with BglII and NheI and used to replace the corresponding fragment in 
Table 2 | Oligonucleotides $\left(5^{\prime} \rightarrow 3^{\prime}\right)^{\mathrm{a}}$.

\begin{tabular}{|c|c|}
\hline 2302Amut-1 & AAGCGCGACGGTGCCACC \\
\hline 2302Amut-2 & AGCGCGCGACGGTCGAGCGTGCCTTCGGCGGTCAGC \\
\hline 2302Amut-3 & GCTGACCGCCGAAGGCACGCTCGACCGTCGCGCGCT \\
\hline 2302Amut-4 & CCGGACTCGCCGGAGCGG \\
\hline XL007 & TCAGTCACATATGAGTGCGTCAGAAGACCTG (Ndel) \\
\hline XL009 & GTCAGCTAGCAGAGCGATGCAGGAGCGACA (Nhel) \\
\hline XL010 & ACTGGAATTCCGGGGTCGTCAGGAAGCGTT (EcoRI) \\
\hline XL032 & ACTGAGATCTGGAAGAGCGTGCTGAAAC (BgIII) \\
\hline XL033 & GTCAGCTAGCGGTTGCCAGGTTCGCCG (Nhel) \\
\hline XL034 & ACTGACTCATATGAGCGCCTCGTTCAG (Ndel) \\
\hline XL036 & ACTGACTCATATGGAACGAACAGCTCCC (Ndel) \\
\hline XL042 & $\begin{array}{l}\text { GTCAGAATTCTCAGTGGTGGTGGTGGTGGTGGGGTTGGTGGACAT } \\
\text { (EcoRI) }\end{array}$ \\
\hline XL044 & $\begin{array}{l}\text { GTCAGAATTCTCAATGATGATGATGATGATGTGCGGCACCTCC } \\
\text { (EcoRI) }\end{array}$ \\
\hline XL046 & TCAGTCACATATG GTGGAATCCCTGGTGGCCGCGT (Ndel) \\
\hline XL094 & CAATTCGGCGATCGCCTGCACGCCCAGCAGTGCATGC \\
\hline XL095 & GCATGCACTGCTGGGCGTGC \\
\hline XL097 & GTCAGAATTCGCTAGCGGTTGCCAGGTTCGCCG (EcoRI, Nhel) \\
\hline XL101 & CGCCCTGATCGGCGCCGCACTCGGCGGCATGC \\
\hline XL102 & GCCGCCGAGTGCGGCGCCGATCAG \\
\hline XL136 & CTCTTCCAGATCTCCAGCAGG (BgIII) \\
\hline XL137 & CTTGATCGAGGACGCGAAGGAGAAC \\
\hline XL138 & CTCCTTCGCGTCCTCGATCAAGCAG \\
\hline XL202 & ACCTCCGGATCCACCGGACG (BamHI) \\
\hline XL203 & GCACCGCCCGCAGGGCATCGCCGCCGGCGGCGTAG \\
\hline XL204 & ACGCCGCCGGCGGCGATGCCCTGCGGGCGGTGCACC \\
\hline XL206 & CTGGATCAGGCGGATGGCGTCGCCGCCGACCTGG \\
\hline XL207 & CTTCCAGGTCGGCGGCGACGCCATCCGCCTGATCCAG \\
\hline XL208 & ACGTGGATCCTACGCCGACCTTCTCGCC (BamHI) \\
\hline $\mathrm{XL} 212$ & ACGTGGATCCGATGTGCTGCTCGGTCTCG (BamHI) \\
\hline $\mathrm{XL213}$ & ACGTGAATTCTCCAGTCGAACGGGGTGGC (EcoRI) \\
\hline
\end{tabular}

a Specified restriction sites are underlined, altered nucleotides are in bold.

pME9714. Plasmid pME10330, which carries mutations in the the $\mathrm{A}$ and in the TE domain, was generated in several steps. First, the primer pairs 2302Amut-1/2302Amut-2 and 2302Amut3/2302A-mut4 were used to generate the codon mutation K1230T. The PCR fragment was then trimmed with NcoI-BglII and used to replace the corresponding fragment in pME9714. The resulting plasmid served as a template in a second overlap extension PCR with XL046/XL137 and XL138/XL36 to generate a fragment specifying the mutations K1230T and D644A. This fragment was then trimmed with PstI and BglII and used to replace the corresponding 2.6-kb fragment in the TE mutant plasmid pME10328.

\section{MUTANT CONSTRUCTION}

Gene replacement mutants of $P$. aeruginosa (Table 1) were generated with suicide plasmids as described previously (Ye et al., 1995). These were constructed as follows. To generate the suicide plasmid pME10326 (for generation of $a m b B_{\mathrm{T} 2302 \mathrm{G}}$ specifying $\mathrm{AmbB}_{\mathrm{S} 768 \mathrm{~A}}$ ), a 2.6-kb fragment was generated from pME9713 by overlap extension PCR using the primer pairs XL202/XL203 and XL204/XL010. This fragment was trimmed with BamHI and EcoRI and cloned into pME3087 between the same sites. For construction of the suicide plasmid pME10338 (to generate $a m b E_{\mathrm{T} 3856 \mathrm{G}}$ specifying $\mathrm{AmbE}_{\mathrm{S} 1286 \mathrm{~A}}$ ), a 1.1-kb PCR fragment was amplified from pME10337 with the primer pair XL212/XL213. This fragment was trimmed with EcoRI and BamHI and cloned into pME3087. Similarly, a 1.8-kb PCR fragment, amplified from pME10317 with the primer pair XL097/XL208 and trimmed with BamHI and EcoRI, was cloned into pME3087 to obtain the suicide plasmid pME10341 (for construction of $a m b E_{\mathrm{T} 5455 \mathrm{G}, \mathrm{G} 5457 \mathrm{~A}}$ specifying $\left.\mathrm{AmbE}_{\mathrm{S1819A}}\right)$. Using pME497 as a helper, the suicide plasmids were mobilized from E. coli DH5 $\alpha$ into P. aeruginosa PAO1 and chromosomally integrated with selection for Tc resistance. Excision of the vector, resulting from a second crossing-over event, was obtained by enrichment for Tc-sensitive cells. Mutant identification was done by PCR and sequence analysis. This generated the mutants PAO6932 (the suicide plasmid used was pME10326), PAO6934 (suicide plasmid pME10338), and PAO6935 (suicide plasmid pME10341).

\section{DETECTION OF AMB PRODUCTION IN $P$. aeruginosa STRAINS}

AMB production of wildtype and mutant strains was assessed using a previously described bioassay, which is based on the growth inhibition of E. coli K-12 (Lee et al., 2010).

\section{PROTEIN PURIFICATION}

Hexahistidine-tagged proteins were purified from $800 \mathrm{ml}$ cultures of E. coli BL21 (DE3)/pLys (for AmbB and AmbE) or E. coli BL21 (DE3; for AmbC, AmbD, and Sfp) carrying the relevant overexpression plasmid (see Table 1). Cultures were set up in four Erlenmeyer flasks containing $200 \mathrm{ml}$ of NYB plus Km. These were inoculated with $3 \mathrm{ml}$ of precultures grown overnight in NYB containing $\mathrm{Km}$ (for overexpression in E. coli BL21 [DE3]) or $\mathrm{Km}+\mathrm{Cm}$ (for overexpression in E. coli BL21 [DE3]/pLys). Growth occurred at $30^{\circ} \mathrm{C}$ and $180 \mathrm{RPM}$ to an $\mathrm{OD}_{600}$ of $0.4-0.5$. For purification of $\mathrm{AmbB}$ and AmbE, IPTG was then added to a final concentration of $0.5 \mathrm{mM}$ and incubation was continued for another $4 \mathrm{~h}$ at $24^{\circ} \mathrm{C}$. For purification of AmbC, AmbD, and Sfp, induction was done with $1 \mathrm{mM}$ IPTG and incubation was continued overnight at $20^{\circ} \mathrm{C}$.

Cells were harvested by centrifugation $\left(8000 \mathrm{RPM}\right.$ at $4^{\circ} \mathrm{C}$ for $15 \mathrm{~min}$ ), washed once with $200 \mathrm{ml}$ of resuspension buffer A (25 mM Tris- $\mathrm{HCl} \mathrm{pH}$ 7.9, $200 \mathrm{mM} \mathrm{NaCl}, 5 \mathrm{mM}$ imidazole, and $5 \mathrm{mM} \beta$-mercaptoethanol), resuspended in $30 \mathrm{ml}$ of the same buffer, and lysed by two passages through a French pressure cell press (SLM-Amicon). To avoid protein modification and interference with subsequent trypsin digests for MS analyses (see below), no protease inhibitor was used. Cell debris was removed by centrifugation (12'000 RPM at $4^{\circ} \mathrm{C}$ for $40 \mathrm{~min}$ ) and proteins were purified from cell lysates by nickel chromatography using Ni-NTA Superflow resin (Qiagen). $3 \mathrm{ml}$ of Ni-NTA slurry was added to the crude cell extract and the sample was rotated at $4^{\circ} \mathrm{C}$ for $1 \mathrm{~h}$ before loading onto a polypropylene column. Column washing occurred with $20 \mathrm{ml}$ of washing buffer $(25 \mathrm{mM}$ Tris- $\mathrm{HCl} \mathrm{pH} 7.9$, $200 \mathrm{mM} \mathrm{NaCl}, 30 \mathrm{mM}$ imidazole, and $5 \mathrm{mM} \beta$-mercaptoethanol) 
and proteins were eluted with $10 \mathrm{ml}$ of elution buffer $1(25 \mathrm{mM}$ Tris- $\mathrm{HCl} \mathrm{pH}$ 7.9, $200 \mathrm{mM} \mathrm{NaCl}, 100 \mathrm{mM}$ imidazole, and $5 \mathrm{mM}$ $\beta$-mercaptoethanol) followed by $10 \mathrm{ml}$ of elution buffer $2(25 \mathrm{mM}$ Tris- $\mathrm{HCl} \mathrm{pH} \mathrm{7.9,} 200 \mathrm{mM} \mathrm{NaCl}, 200 \mathrm{mM}$ imidazole, and $5 \mathrm{mM} \beta$ mercaptoethanol). Fractions of $1 \mathrm{ml}$ were collected and analyzed for the presence of the hexahistidine-tagged protein by sodium dodecyl sulfate-polyacrylamide gel electrophoresis (SDS-PAGE). For AmbC and AmbD, EDTA was added to each eluant fraction to a final concentration of $1 \mathrm{mM}$ to chelate metal ions. Fractions with pure $(\geq 90 \%)$ hexahistidine-tagged protein were pooled and dialyzed using a regenerated cellulose membrane (3500 molecular weight cutoff, Spectra/Por, Spectrum Laboratories) against 2 lt of dialysis buffer [25 mM Tris- $\mathrm{HCl} \mathrm{pH} \mathrm{7.9,} 200 \mathrm{mM} \mathrm{NaCl}$, 10\% glycerol, $0.5 \mathrm{mM} \beta$-mercaptoethanol (for AmbB, AmbE, and Sfp) and $25 \mathrm{mM}$ Tris- $\mathrm{HCl} \mathrm{pH}$ 7.9, $200 \mathrm{mM} \mathrm{NaCl}, 10 \%$ glycerol (for AmbC and AmbD)]. Proteins were subsequently concentrated with Amicon Ultra centrifugal filters with molecular weight cutoffs of 10'000 (for AmbC, AmbD, and Sfp) or 50'000 (for AmbB and AmbE). Concentrated proteins ( $\sim 20 \mathrm{mg} / \mathrm{ml}$, as determined by Nanodrop) were flash-frozen in liquid nitrogen and stored in aliquots at $-80^{\circ} \mathrm{C}$.

\section{ATP-[32P]PYROPHOSPHATE EXCHANGE ASSAYS}

ATP- $\left[{ }^{32} \mathrm{P}\right]$ pyrophosphate exchange assays were used to demonstrate A-domain substrate specificity. Reactions were carried out in $100 \mu \mathrm{l}$ volumes containing $75 \mathrm{mM}$ Tris- $\mathrm{HCl}(\mathrm{pH} 7.5), 10 \mathrm{mM}$ $\mathrm{MgCl}_{2}, 0.5 \mathrm{mM}$ tris(2-carboxyethyl)phosphine (TCEP), $5 \mathrm{mM}$ ATP, $1 \mathrm{mM}$ tetrasodium pyrophosphate, $1 \mathrm{mM}$ of amino acid and $20 \mu \mathrm{l}$ of tetrasodium $\left[{ }^{32} \mathrm{P}\right.$ ]pyrophosphate $(5 \mathrm{mM}, 2 \mu \mathrm{Ci} / \mu \mathrm{mol}$, NEN-Perkin Elmer). Reactions were initiated by the addition of enzyme at $1 \mu \mathrm{M}$ and incubated at $24^{\circ} \mathrm{C}$ for $2 \mathrm{~h}$. At appropriate time points, reactions were quenched by the addition of $0.5 \mathrm{ml}$ of charcoal suspension $(0.1 \mathrm{M}$ tetrasodium pyrophosphate, $0.35 \mathrm{M}$ perchloric acid, $1.6 \%(\mathrm{w} / \mathrm{v})$ activated charcoal). Free $\left[{ }^{32} \mathrm{P}\right]$ pyrophosphate was removed by centrifugation and the charcoal pellet was washed twice with wash solution $(0.1 \mathrm{M}$ tetrasodium pyrophosphate, $0.35 \mathrm{M}$ perchloric acid). Charcoal-bound radioactivity was measured in a Beckman LS 6500 scintillation counter.

\section{PHOSPHOPANTETHEINYLATION AND AMINOACYLATION ASSAYS}

T-domain loading was assayed using an aminoacylation assay. Apoenzymes (at $2.5 \mu \mathrm{M}$ ) were first incubated in $75 \mathrm{mM}$ Tris$\mathrm{HCl} \mathrm{pH}$ 7.5, $5 \mathrm{mM} \mathrm{MgCl}_{2}$, $5 \mathrm{mM}$ TCEP, $40 \mathrm{mM} \mathrm{NaCl}, 0.5 \mathrm{mM}$ CoA with $1.5 \mu \mathrm{M}$ of purified promiscuous phosphopantetheinyl transferase Sfp at $28^{\circ} \mathrm{C}$ for $60 \mathrm{~min}$ for conversion of the apo- to the holo-form. Subsequently, ${ }^{14} \mathrm{C}$-labeled substrate amino acids were added to a final concentration of $10 \mu \mathrm{M}$ (L-Ala) or $50 \mu \mathrm{M}$ (L-Glu) and aminoacylation reactions started with the addition of ATP to a final concentration of $10 \mathrm{mM}$. At defined time points, samples were drawn and quenched into $800 \mu \mathrm{l}$ of $10 \%(\mathrm{v} / \mathrm{v})$ trichloroacetic acid (TCA) and $100 \mu \mathrm{l}$ of $1 \mathrm{mg} / \mathrm{ml}$ BSA. Precipitated proteins were pelleted by centrifugation at 13'000 RPM for $10 \mathrm{~min}$. Protein pellets were washed once with $800 \mu 1$ 10\% TCA and finally dissolved in $250 \mu \mathrm{l}$ formic acid. ${ }^{14} \mathrm{C}$-bound radioactivity was measured by liquid scintillation counting using a Beckman LS 6500 scintillation counter.

\section{GENERATION OF ENZYME-ATTACHED AMB SUBSTRATES AND PRECURSOR PEPTIDES FOR MS ANALYSIS}

Apoenzymes (at $2.5 \mu \mathrm{M}$ ) were incubated with Sfp as described above to generate their holoforms. After $60 \mathrm{~min}$, the reaction mixture was supplemented with $10 \mathrm{mM}$ ATP and $1 \mathrm{mM}$ of the substrate amino acid(s). For modification of the growing peptide chain, additional enzymes, and potential cofactors were added at the following concentrations: $2.5 \mu \mathrm{M}$ each of AmbC and AmbD, $1 \mathrm{mM}$ each of $S$-adenosylmethionine (SAM), and $\alpha$ ketoglutarate $(\alpha-\mathrm{KG})$, and $0.5 \mathrm{mM}$ of ferrous iron (supplied as $\left[\mathrm{NH}_{4}\right]_{2} \mathrm{Fe}\left[\mathrm{SO}_{4}\right]_{2}$. Samples were incubated at $28^{\circ} \mathrm{C}$ for another $2 \mathrm{~h}$, supplemented with $10 \%$ glycerol, and stored at $-80^{\circ} \mathrm{C}$ until analysis by MS.

For substrate identification, holoenzymes, and ATP were incubated not with a single, defined amino acid but with a pool of all 20 proteinogenic amino acids (each at $0.5 \mathrm{mM}$ final concentration) or with a $P$. aeruginosa metabolome prepared as described previously for E. coli (Dorrestein et al., 2006).

\section{MS ANALYSIS}

MS analyses were performed by the Protein Analysis Facility (University of Lausanne). Frozen protein samples were thawed and digested by trypsin using a protocol for short digestion time (Hollenhorst et al., 2010). Briefly, $5 \mu$ l of proteins were digested at $30^{\circ} \mathrm{C}$ for $60 \mathrm{~min}$ under agitation with $281.3 \mathrm{ng}$ of modified sequencinggrade porcine trypsin (Promega) at a protein:trypsin ratio of about 10:1 (w/w) in $50 \mu \mathrm{l}$ of $50 \mathrm{mM}$ ammonium bicarbonate. Digestion was stopped by adding $2 \mu \mathrm{l}$ of $10 \%$ formic acid, and samples were dried by speed-vacuum. Samples were then resuspended in $50 \mu \mathrm{l}$ of $\mathrm{H}_{2} \mathrm{O}: \mathrm{MeCN}$ 97:3 (v/v) + 0.1\% formic acid.

The tryptic peptide samples were analyzed by high resolution liquid chromatography coupled with MS (LC-MS/MS) on an Ultimate 3000 RSLCnano HPLC system coupled to a hybrid linear trap LTQ-Orbitrap XL mass spectrometer (Thermo Scientific). Solvents used were (A) $\mathrm{H}_{2} \mathrm{O}: \mathrm{MeCN} 97: 3(\mathrm{v} / \mathrm{v})+0.1 \%$ formic acid and (B) $\mathrm{H}_{2} \mathrm{O}: \mathrm{MeCN} 20: 80(\mathrm{v} / \mathrm{v})+0.1 \%$ formic acid. A volume of $5 \mu \mathrm{l}$ of sample was loaded onto a trapping microcolumn Acclaim PepMap $100 \mathrm{C} 18$ ( $2 \mathrm{~cm} \times 100 \mu \mathrm{m}$, Dionex $)$ in $\mathrm{H}_{2} \mathrm{O}$ :MeCN 97:3 $(\mathrm{v} / \mathrm{v})+0.1$ formic acid at a flow rate of $3.5 \mu \mathrm{l} / \mathrm{min}$. Peptides were then eluted and separated on a reversed-phase Acclaim PepMap RSLC C18 nanocolumn $(75 \mu \mathrm{m}$ ID $\times 15 \mathrm{~cm}, 2 \mu \mathrm{m}$, Dionex $)$ or a Nikkyo C18 nanocolumn $(75 \mu \mathrm{m}$ ID $\times 15 \mathrm{~cm}, 3 \mu \mathrm{m}$, Nikkyo Technos) with a $95 \mathrm{~min}$ gradient, at a flow rate of $300 \mathrm{nl} / \mathrm{min}$. In data-dependent acquisition controlled by Xcalibur 2.0 software (Thermo Scientific), the eight most intense precursor ions detected in the full MS survey performed in the Orbitrap (range $350-1700$ mass/charge $(\mathrm{m} / z)$ ratio, resolution 60000 at $\mathrm{m} / z 400)$ were selected for fragmentation, and fragment ions were analyzed in the ion trap. $\mathrm{MS}^{2}$ was triggered by a minimum signal threshold of 10 ' 000 counts and carried out at relative collision energy of 35\% (CID), with an isolation width of $4.0 \mathrm{amu}$. Only precursors with a charge higher than one were selected for fragmentation and the $\mathrm{m} / \mathrm{z}$ of fragmented precursors was then dynamically excluded from any selection during $60 \mathrm{~s}$. $\mathrm{MS}^{3}$ analyses were further carried out for specific detection of phosphopantetheinylated (PPant) peptides as described by Meier et al. (2011). Briefly, following MS $^{2}$ of the most intense precursor ion from an inclusion list, the two 
most intense fragment ions were selected for $\mathrm{MS}^{3}$ fragmentation in the ion trap, if their mass was present in an inclusion list of pantetheine fragments and above a signal threshold of 100 counts in the MS/MS spectrum.

MS/MS spectra were analyzed using Mascot 2.4 (Matrix Science, London, UK). Mascot driven search was set up against a custom-built database containing the $P$. aeruginosa sequences of wild-type and mutated AmbE and AmbB, and the sequences of usual contaminants (enzymes, keratins, etc). Trypsin (semispecific cleavage at $\mathrm{K}, \mathrm{R}$, not before $\mathrm{P}$ ) was used as the enzyme digestion definition allowing up to two missed cleavages. Mascot was searched with a parent ion tolerance of $10 \mathrm{ppm}$ and a fragment ion mass tolerance of $0.5 \mathrm{Da}$. Acetylation at protein N-terminal, deamidation of asparagine, and glutamine, oxidation of methionine, and phosphopantetheine addition to serine were specified as variable modifications.

\section{BIOINFORMATICS ANALYSIS}

DNA and protein sequences were obtained from the $P$. genome database (Winsor etal., 2011) and the protein and genome databases available on the NCBI website ${ }^{1}$. Protein sequences were analyzed on the polyketide synthase/NRPS analysis website (Bachmann and Ravel, 2009) and searched against the Conserved Domain Database using the CD-search algorithm on the NCBI website (Marchler-Bauer and Bryant, 2004). C-domain phylogenetic analysis was performed using the ClustalW algorithm (Thompson etal., 1994) available on the server of the Kyoto University Bioinformatics Center ${ }^{2}$. Results were displayed as an unrooted N-J phylogenetic tree (Saitou and Nei, 1987).

\section{RESULTS}

\section{DOMAIN ARCHITECTURE OF AmbB AND AmbE}

Sequence inspection of $A m b B$ and AmbE suggested that these enzymes are NPRSs that generate a AMB precursor peptide by a thiotemplate mechanism (Stein etal., 1996). NRPSs can be dissected into modules, each module being responsible for the incorporation of one amino acid or carboxy acid into the growing peptide chain. In turn, each module consists of domains, which are enzymatic units that catalyze the stepwise addition and modification of the amino/carboxy acid. In some cases, the biosynthesis of a non-ribosomal peptide (NRP) can be predicted from the analysis of these domains provided that biosynthesis follows the colinearity rule (Marahiel et al., 1997). Bioinformatics analysis showed that the AmbB protein is composed of three domains, which are responsible for adenylation (A domain) of a substrate amino acid, for loading of this amino acid onto a phosphopantetheine arm attached at a conserved serine ( $\mathrm{T}$ domain), and for condensation ( $\mathrm{C}$ domain) of this amino acid with a second amino acid bound at the T domain of another module (Figure 1). The modular structure of AmbE is more complex and consists of an A domain, two $\mathrm{T}$ domains (T1 and T2), a C domain (indicated as $\mathrm{C}^{*}$ in Figure 1), a domain for methylation (MT domain) and a domain for thioester cleavage (TE domain). Moreover, it cannot be ruled out that an additional domain of unknown function may be

\footnotetext{
${ }^{1}$ www.ncbi.nlm.nih.gov

${ }^{2}$ http://www.genome.jp/tools/clustalw/
}

located at the N-term of AmbE (Figure 1) given that this consists of a stretch of 461 amino acids. However, no similar domain architectures have been identified in this region using the Conserved Domains algorithm. Phylogenetic analyses of the $C^{*}$ domain suggest a new or additional function of this $\mathrm{C}$ domain, as it does not group with previously known L2L, D2L, epimerization, heterocyclization, dual condensation/epimerization, or starter $\mathrm{C}$ domains (Figure $\mathrm{S} 1$ ). The $\mathrm{C}^{*}$ domain rather groups with another atypical $\mathrm{C}$ domain found in the McyA protein of Microcystis aeruginosa (Tillet et al., 2000). However, the biochemical function of McyA has not been studied experimentally. We conclude from these analyses that the two peptide synthetases AmbB and AmbE likely generate a tripeptide. This peptide is suspected to undergo a series of modification steps carried out by tailoring domains of AmbE (MT domain, N-term domain, $\mathrm{C}^{*}$ domain), and by the hydroxylases AmbC and AmbD. Finally, the tripeptide would be released from the thiotemplate by thioester cleavage (TE domain).

\section{OVEREXPRESSION AND PURIFICATION OF THE AMB BIOSYNTHESIS PROTEINS AmbB, AmbC, AmbD, AND AmbE}

To study AMB biosynthesis with purified enzymes in vitro, the $a m b B C D E$ genes (and their mutated derivatives, see below) were cloned under the control of the T7 promoter in pET-28a or pET27b (Table 1). Proteins were purified from E. coli BL21(DE3; for AmbC and AmbD) and BL21(DE3)/pLys (for AmbB and $\mathrm{AmbE}$ ) with a hexahistidine tag at their N-terminus (AmbB) or C-terminus (AmbC, AmbD, and AmbE). According to analysis on SDS-PAGE gels all proteins were $\geq 90 \%$ pure (Figure 2 ).

\section{IDENTIFICATION OF L-ALA AS THE AMINO ACID SUBSTRATE OF AmbB}

Based on the presence of key residues found in the A-domains of peptide synthetases, it is often possible to predict their amino acid specificity (Stachelhaus et al., 1998). Predictions of A domain specificity in AmbB favors the activation of L-Ala but certain residues of the binding pocket have also been found in $\mathrm{D}$-alanine (D-Ala) activating A domains of other peptide synthetases. We therefore tested which of the two isomers would be activated by AmbB using an ATP- $\left[{ }^{32} \mathrm{P}\right]$ pyrophosphate exchange reaction. In addition, we also investigated whether other small amino acids such as glycine (Gly) or L-serine (L-Ser) would be activated. As shown in Figure 3A, AmbB activated preferentially L-Ala, giving an exchange activity of 653 at $5 \mathrm{~min}$ already. Hower, L-Ser, Gly, and D-Ala were activated as well, albeit to a lower extent. Exchange activities measured at 5 min were 270, 128, and 114 for L-Ser, Gly, and D-Ala, respectively (Figure 3A). To further specifiy the amino acid substrate, we next investigated $\mathrm{T}$ domain loading of AmbB. For this, proteins were incubated first with CoA and the promiscuous phosphopantetheinyltransferase Sfp of Bacillus subtilis for phosphopantetheinylation of the $\mathrm{T}$ domain. Loading was then monitored by measuring the incorporation of ${ }^{14} \mathrm{C}$-labeled amino acids into $\mathrm{AmbB}$ (and $\mathrm{AmbB}_{\mathrm{S} 768 \mathrm{~A}}$, see below) by TCA precipitation and liquid scintillation counting. As shown in Figure 3B, loading of AmbB with ${ }^{14} \mathrm{C}$-L-Ala occurred very quickly, reaching a maximum of $35-40 \%$ after 1 min only. By contrast, no loading was observed with $\mathrm{AmbB}_{\mathrm{S} 768 \mathrm{~A}}$. In this protein, the active site Ser in the conserved thiolation motif LGG(H/D)S(L/I; Stein et al., 1996) was altered, thus preventing cofactor attachment and hence loading of 

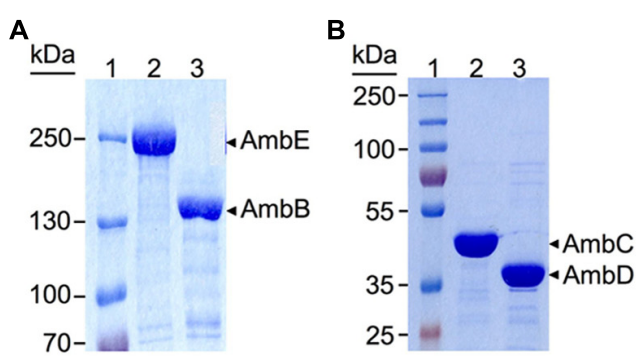

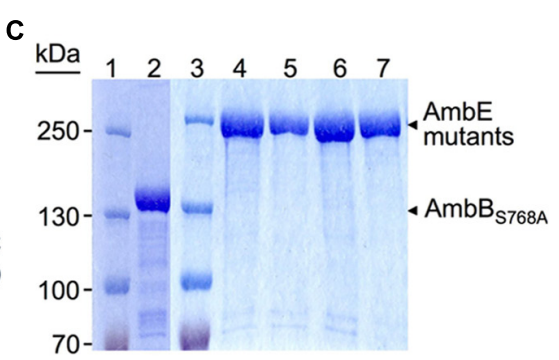

FIGURE 2 | Sodium dodecyl sulfate-polyacrylamide gel electrophoresis (SDS-PAGE) analysis of hexahistidine-tagged proteins purified by Ni-NTA chromatography. (A) 6\% Separating gel with protein ladder (lane 1), and $\mathrm{AmbE}$ (231.5 KDa, lane 2) and $\mathrm{AmbB}(137 \mathrm{KDa}$, lane 3) purified from BL21[DE3]/pLys carrying pME9714 and pME9713, respectively. (B) 10\% Separating gel with protein ladder (lane 1), and $\mathrm{AmbC}(41.5 \mathrm{KDa}$, lane 2), and AmbD (39.5 KDa, lane 3) purified from BL21[DE3] carrying pME9718 and
pME9717, respectively. (C) $6 \%$ Separating gels of purified mutant proteins. Lanes 1 and 3, protein ladders; lane 2, AmbB 3768 A expressed from pME10327; lane 4, AmbE $\mathrm{D}_{\mathrm{D} 44 \mathrm{~A}, \mathrm{~K} 1230 \mathrm{~T}, \mathrm{~S} 1958 \mathrm{~A}}$ expressed from pME10330; lane 5, AmbE $\mathrm{S}_{\mathrm{S} 1958 \mathrm{~A}}$ expressed from pME10328; lane 6, AmbE $\mathrm{S}_{\mathrm{S1819A}}$ expressed from pME10317; lane 7, AmbE $\mathrm{S1286A}_{\text {A }}$ expressed from pME10337. All proteins were purified from BL21[DE3]/pLys carrying the respective plasmid.
L-Ala. The importance of Ser 768 of AmbB was also tested in vivo. As expected, a $P$. aeruginosa strain (PAO6932) with a chromosomally mutated $a m b B$ gene (specifying $A_{m b B} b_{S 68 A}$ ) lost the ability to make AMB (Figure S2).

As ATP- $\left[{ }^{32} \mathrm{P}\right]$ pyrophosphate exchange reactions had revealed some activation of Gly and L-Ser by AmbB (Figure 3A), we tested whether these amino acids would be loaded as well. Indeed, loading was observed for both of them but to a lesser extent than with L-Ala (Figure 3C). Taken together, we conclude that the preferred substrate of AmbB is L-Ala and that this amino acid is loaded onto the phosphopantetheine arm attached at Ser 768.

\section{ACTIVATION AND LOADING OF L-GLU BY AmbE}

Unlike with AmbB, an exact prediction of the amino acid substrate for AmbE was not evident from the Stachelhaus motif. As this motif predicted a polar residue, we first considered L- $\alpha$-aminobutyrate, L-homoserine, L-aspartate, and L-threonine as $\mathrm{AMB}$ precursor amino acids. However, none of these amino acids was activated in an ATP- $\left[{ }^{32} \mathrm{P}\right]$ pyrophospate exchange assay (data not shown). We next tested $\mathrm{D}$ - $\alpha$-aminobutyrate, L-allothreonine, D-threonine, L-Glu, O-phospho-L-threonine, DLpropargylglycine, DL-vinylglycine, and L-2-amino-4-pentenoic acid. As shown in Figure 4A, strong activation of L-Glu was observed. We therefore tested whether L-Glu would be loaded onto AmbE and found that this was indeed the case (Figure 4B). By contrast, no loading of L-Glu was observed with the mutant $\mathrm{AmbE}_{\mathrm{D} 644 \mathrm{~A}, \mathrm{~K} 1230 \mathrm{~T}}$ affected in the adenylation domain (Figure 4C). To investigate on which of the two T domains L-Glu would be loaded, we carried out loading assays with AmbE $1286 \mathrm{~A}$

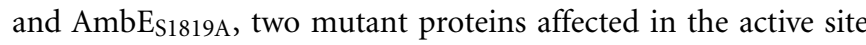
Ser residues of the $\mathrm{T} 1$ and $\mathrm{T} 2$ domains, respectively. As shown in Figure 4B, loading was observed with $A_{m b E_{S 1819 A}}$ but not with $A m b E_{S 1286 A}$. To verify that both Ser residues are important for cofactor attachment, we mutated the respective codons in the chromosome of P. aeruginosa, giving PAO6934 and PAO6935, respectively. As expected, both strains had lost the ability to make AMB (Figure S2). We thus conclude that the A domain of AmbE activates L-Glu, which is then loaded onto T1 but not onto $\mathrm{T} 2$.

\section{AmbB-DEPENDENT LOADING OF L-ALA ONTO THE T2 DOMAIN OF AmbE} The identity of the substrate loaded onto the T2 domain of AmbE was investigated using MS-based activity screening (Dorrestein et al., 2006; Meier et al., 2011). This method allows substrate identification based on the mass changes that take place during the acylation of the $\mathrm{T}$ domain-attached phosphopantetheine arm (Figure 5A). AmbE, together with AmbB (which was included in the same experiment as an internal control), was presented either with a mixture of all 20 natural amino acids or with a $P$. aeruginosa metabolome before being digested with trypsin and analyzed by LC-MS/MS (see Section "Materials and Methods" for experimental details). Similar results were obtained in both cases. The phosphopantetheinylated AmbB peptide AGQGFYAAGGDSLR presented a mass shift of +71.04 indicative of Ala loading onto the $\mathrm{T}$ site of AmbB (Figure 5B; Table 3). In agreement with the protein's previously observed substrate promiscuity, the same peptide also showed mass shifts characteristic for loading of Gly (57.02; Figure S3A; Table 3) and Ser (87.03; Figure S3B; Table 3). To identify the substrates loaded onto AmbE, mass shifts of the phosphopantetheinylated peptides RPAIGVSDNFFQVGGDSIR (T1 domain) and VLGRPLAADQGFASAGGHSLLGVQAIAELR (T2 domain) were analyzed. As expected, we found a Glu-specific mass shift of +129.04 for the T1-specific peptide (Figure S4A; Table 3). For the T2-specific peptide we detected a mass shift of +71.04 (Figure S4B; Table 3), indicating that the substrate amino acid loaded at the second $\mathrm{T}$ domain of AmbE could be Ala.

The potential identity of the T2-attached substrate with Ala suggested that this amino acid may have been loaded in trans from AmbB. This hypothesis was tested using the AmbB $\mathrm{B}_{\mathrm{S}} 68 \mathrm{~A}$ mutant protein which is able to activate L-Ala but cannot load it onto its own T domain (see Figure 3B). As shown in Figure 6, the presence of $\mathrm{AmbB}_{\mathrm{S} 768 \mathrm{~A}}$ in an aminoacylation assay of AmbE allowed ${ }^{14} \mathrm{C}-\mathrm{L}$ Ala to be loaded, reaching a maximum of over $60 \%$ labeled protein after $30 \mathrm{~min}$. By contrast, no loading was observed in the absence of $\mathrm{AmbB}_{\mathrm{S} 768 \mathrm{~A}}$ or when $\mathrm{AmbE}$ was replaced by the T2 domain mutant AmbE $1819 \mathrm{~A}$. We thus conclude that AmbB loads L-Ala in cis onto its own $\mathrm{T}$ domain and in trans onto the T2 domain of AmbE. 

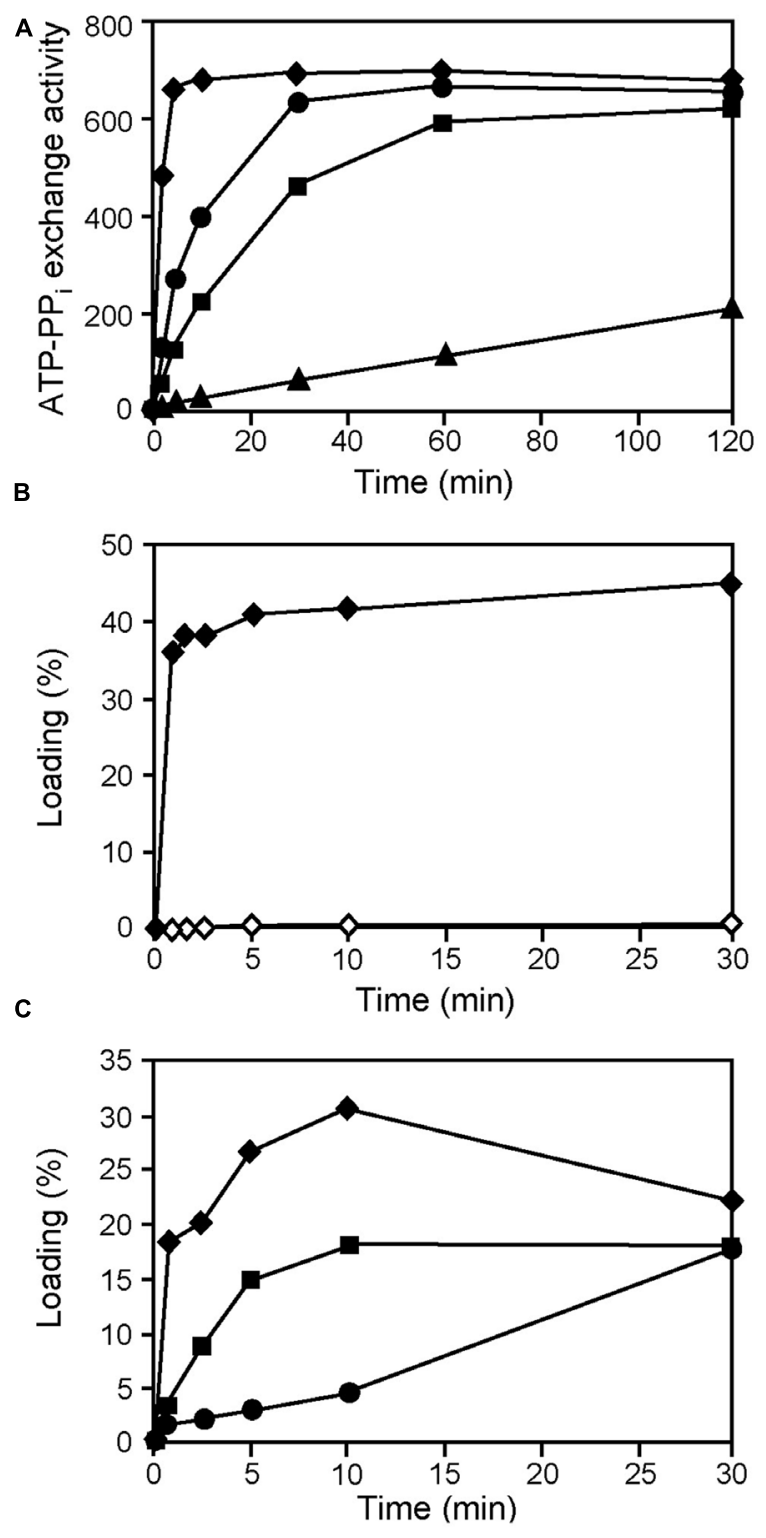

FIGURE 3 | Identification of L-Ala as the preferred amino acid substrate activated by and loaded onto AmbB. (A) AmbB activation of L-Ala (diamonds), D-Ala (triangles), Gly (rectangles), and L-Ser (circles). AmbB was incubated sequentially with each amino acid in an ATP-[32P] pyrophosphate exchange assay. At different time points, generated ATP (formed by the reverse reaction of the AmbB A domain in the presence of $\left.{ }^{32} \mathrm{P}\right]$ pyrophosphate) was bound and counted. ATP-PP $i$ exchange activity was determined for the full course of the assay and is expressed as the amount of conversion (one being $100 \%$ conversion) multiplied by the molar ratio of $\mathrm{PP}_{\mathrm{i}}$ to $\mathrm{AmbB}$. (B) Loading of ${ }^{14} \mathrm{C}$-L-Ala onto $\mathrm{AmbB}$ (filled diamonds) and $\mathrm{AmbB}_{\mathrm{S} 768 \mathrm{~A}}$ (empty diamonds). Proteins were incubated with radiolabeled L-Ala in an aminoacylation assay. At several time points, proteins (with bound amino acids) were precipitated and radioactivity was counted. Percentage of loading was determined using the molar ratio of bound radioactivity to the amount of protein in the assay. (C) Loading of L-Ala, Gly, and L-Ser onto AmbB. AmbB was sequentially incubated with ${ }^{14} \mathrm{C}$-L-Ala (diamonds), ${ }^{14} \mathrm{C}$-Gly (rectangles), and ${ }^{14} \mathrm{C}$-L-Ser (circles) in an aminoacylation assay. At several time points, AmbB (with bound amino acids) was precipitated and radioactivity was counted. Percentage of loading was determined using the molar ratio of bound radioactivity to the amount of protein in the assay.
A

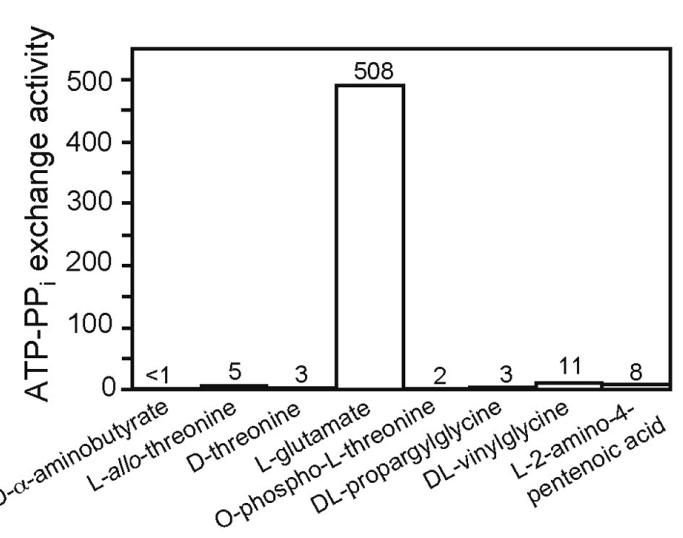

B

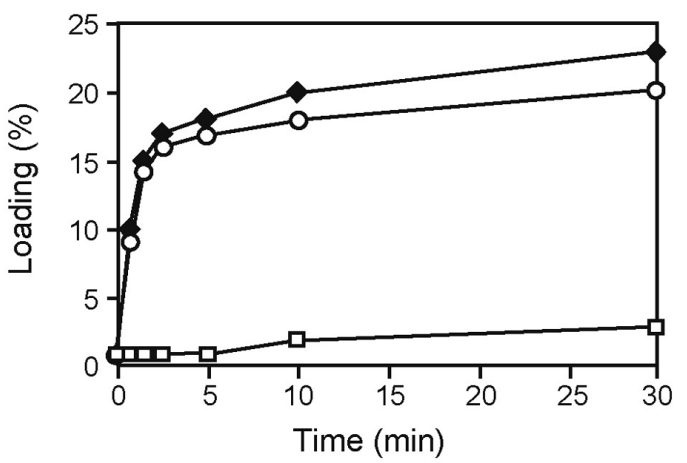

C

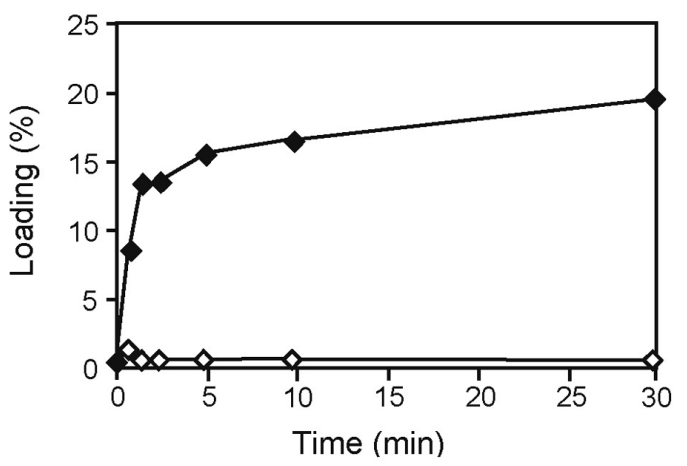

FIGURE 4 | Identification of L-Glu as the amino acid substrate activated by AmbE and loaded onto its T1 domain. (A) End-point ATP-[32P]

pyrophosphate exchange assay to screen potential AmbE substrates. At 120 min, generated ATP (formed by the reverse reaction of the A domain of $A m b E$ in the presence of [ $\left.{ }^{32} \mathrm{P}\right]$ pyrophosphate) was bound and counted. ATP-PP $i$ exchange activity is expressed as the amount of conversion (one being $100 \%$ conversion) multiplied by the molar ratio of $\mathrm{PP}_{\mathrm{i}}$ to $\mathrm{AmbE}$. (B) Loading of ${ }^{14} \mathrm{C}$-L-Glu onto AmbE (filled diamonds), AmbE $1286 \mathrm{~A}$ (empty rectangles), and $\mathrm{AmbE}_{\mathrm{S} 1819 \mathrm{~A}}$ (empty circles). Proteins were incubated with the radiolabeled amino acid in an aminoacylation assay. At several time points, proteins (with bound amino acids) were precipitated and radioactivity was counted. Percentage of loading was determined using the molar ratio of bound radioactivity to the amount of protein in the assay. (C) Mutations in the A domain of AmbE abolish protein loading with L-Glu. $\mathrm{AmbE}_{\mathrm{S1958A}}$ (filled diamonds), and AmbE $\mathrm{D}_{\mathrm{D} 644 \mathrm{~A}, \mathrm{~K} 1230 \mathrm{~T}, \mathrm{S1958A} \text { (empty }}$ diamonds) were incubated with ${ }^{14} \mathrm{C}$-L-Glu in an aminoacylation assay. At several time points, proteins (with bound amino acids) were precipitated and radioactivity was counted. Percentage of loading was determined using the molar ratio of bound radioactivity to the amount of protein in the assay. Note that the mutation of the active site Ser (S1958) of the TE domain does not interfere with loading of L-Glu. By contrast, amino acid alterations in the A domain (D644A and K1230T) abolished loading entirely. 
A

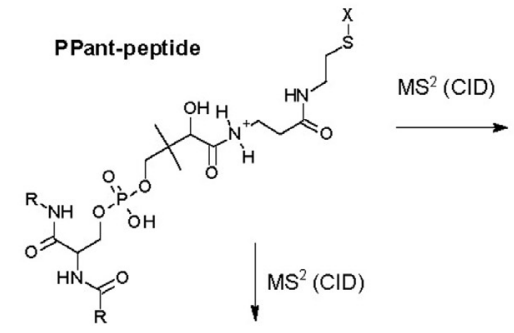

PPant ejection ion 2: phosphopantetheine (phPant-X)

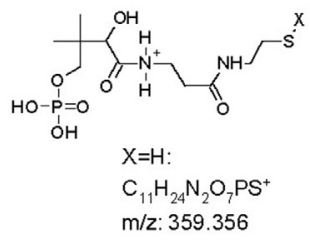

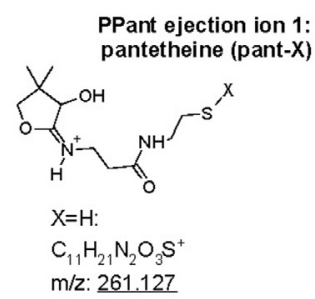

$$
\begin{aligned}
& \text { m/z } \\
& \text { 243.116: } \mathrm{C}_{11} \mathrm{H}_{19} \mathrm{~N}_{2} \mathrm{O}_{2} \mathrm{~S}^{+} \\
& \text {231.116: } \mathrm{C}_{10} \mathrm{H}_{19} \mathrm{~N}_{2} \mathrm{O}_{2} \mathrm{~S}^{+} \\
& \text {215.121: } \mathrm{C}_{10} \mathrm{H}_{19} \mathrm{~N}_{2} \mathrm{OS}^{+} \\
& \text {184.097: } \mathrm{C}_{9} \mathrm{H}_{14} \mathrm{NO}_{3}^{+} \\
& \text {175.054: } \mathrm{C}_{6} \mathrm{H}_{11} \mathrm{~N}_{2} \mathrm{O}_{2} \mathrm{~S}^{+} \\
& \text {166.086: } \mathrm{C}_{9} \mathrm{H}_{12} \mathrm{NO}_{2}^{+} \\
& \text {159.059: } \mathrm{C}_{6} \mathrm{H}_{11} \mathrm{~N}_{2} \mathrm{OS}^{+} \\
& \text {149.074: } \mathrm{C}_{5} \mathrm{H}_{13} \mathrm{~N}_{2} \mathrm{OS}^{+}
\end{aligned}
$$

B
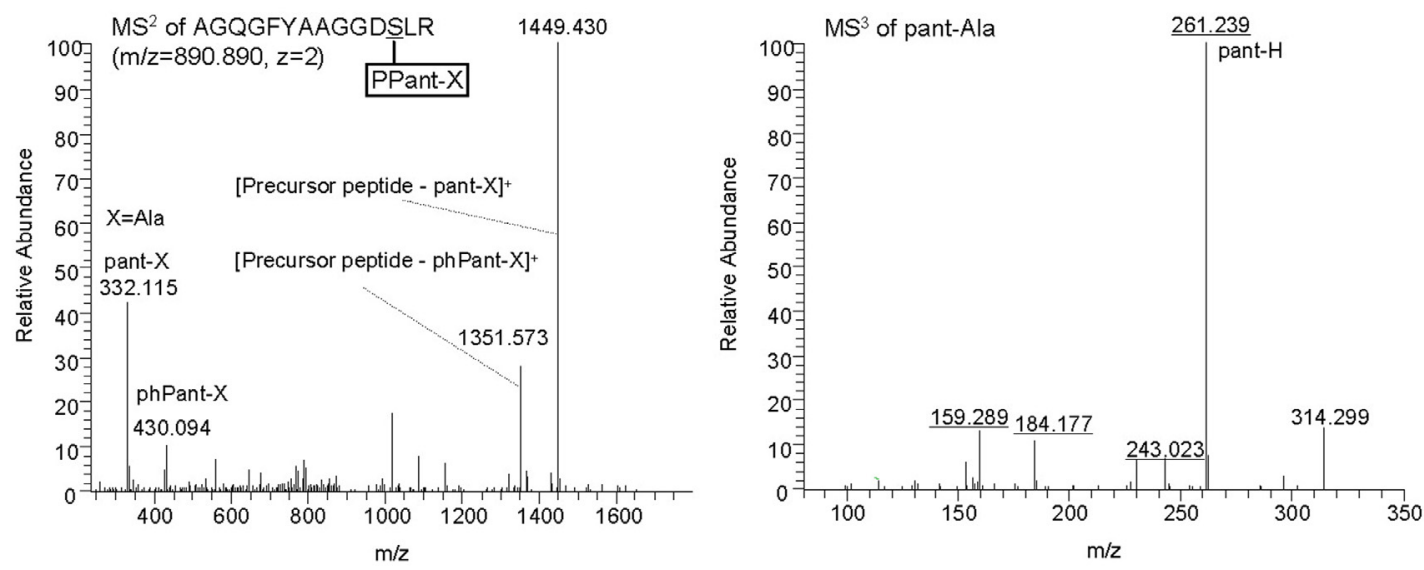

C
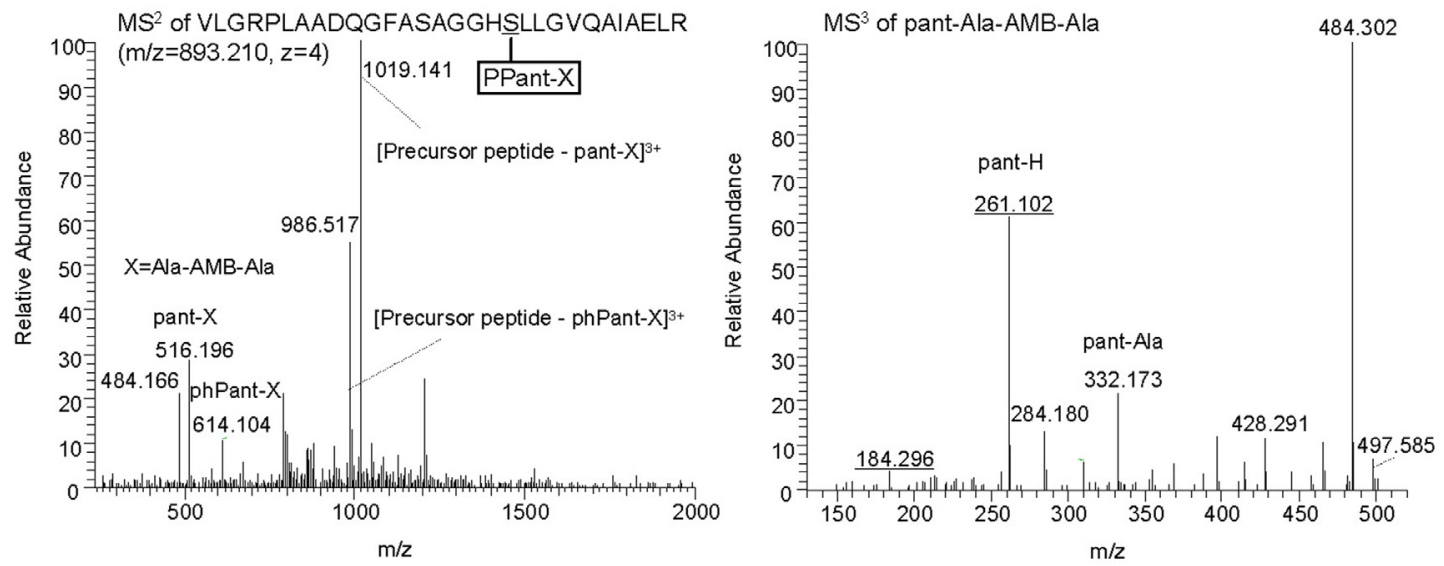

FIGURE 5 | Identification of AmbB/AmbE-bound substrates and pathway intermediates by phosphopantetheinyl elimination reactions.

(A) Structure of PPant ejection ions after $\mathrm{MS}^{2}$ fragmentation and pantetheine-specific MS $^{3}$ pattern (adapted from Meluzzi et al., 2008; Meier et al., 2011). Diagnostic $\mathrm{m} / \mathrm{z}$ values obtained in $B$ and $C$ are underlined. (B) Identification of Ala on $\mathrm{AmbB}$ by characteristic $\mathrm{MS}^{2}$ and $\mathrm{MS}^{3}$ spectra. AmbB and AmbE (at $2.5 \mu \mathrm{M}$; converted to their holo-forms by Sfp) were

incubated with $0.5 \mathrm{mM}$ of all 20 proteinogenic amino acids before trypsin digestion and analysis by MS. (C) Identification of Ala-AMB-Ala on AmbE by characteristic $\mathrm{MS}^{2}$ and $\mathrm{MS}^{3}$ spectra. The assay contained $\mathrm{AmbB}, \mathrm{AmbC}$, $A m b D$, and $A_{m b} E_{S 1958 A}$ (at $2.5 \mu \mathrm{M}$; the two NRPSs were converted to their holo-forms by Sfp), L-Ala and L-Glu (at $1 \mathrm{mM}$ ), as well as the cofactors SAM, $\alpha-K G(a t 1 \mathrm{mM}$ ) and ferrous iron (at $0.5 \mathrm{mM}$ ). After incubation, the sample was treated with trypsin and analyzed by MS. 
Table 3 | AmbB and AmbE peptides with AMB substrates and pathway intermediates loaded via phosphopantetheine.

\begin{tabular}{|c|c|c|c|c|c|}
\hline Peptide $^{a}$ & $\begin{array}{l}\text { Substrate or pathway } \\
\text { intermediate X loaded } \\
\text { (theoretical mass) }\end{array}$ & $\begin{array}{l}\text { Theoretical m/z } \\
\text { (z) (monoisotopic } \\
\text { mass) }\end{array}$ & $\begin{array}{l}\text { Observed } \mathrm{m} / \mathrm{z} \\
(\Delta \mathrm{m} \mathrm{ppm})\end{array}$ & $\mathrm{m} / \mathrm{z}$ pant-X & $\begin{array}{l}\text { Amb enzymes required for } \\
\text { detection of attached compound }\end{array}$ \\
\hline AGQGFYAAGGDSLLR & Gly (57.021) & $883.883(2)$ & $883.881(-2.3)$ & 318.1 & AmbB \\
\hline \multirow[t]{2}{*}{ (AmbB, T domain) } & Ala (71.037) & $890.891(2)$ & $890.890(-1.1)$ & 332.2 & $\mathrm{AmbB}$ \\
\hline & Ser (87.032) & $898.889(2)$ & $898.886(-3.3)$ & 348.2 & $\mathrm{AmbB}$ \\
\hline (AmbE, T1 domain) & Glu-Ala (200.080) & $859.071(3)$ & $859.072(1.2)$ & 461.2 & $A m b B+A m b E_{S 1819 A}{ }^{b}$ \\
\hline VLGRPLAADOGFASAG & Ala (71.037) & $847.192(4)$ & $847.189(-3.5)$ & 332.2 & $\mathrm{AmbB}+\mathrm{AmbE} / \mathrm{Amb} \mathrm{E}_{\mathrm{S} 1819 \mathrm{~A}} \mathrm{~b}$ \\
\hline GHSELLGVQAIAELR & Ala-AMB-Ala (255.121) & $893.212(4)$ & $893.210(-2.2)$ & 516.2 & $A m b B+A m b C+A m b D+A m b E_{S 1819 A}{ }^{b}$ \\
\hline (AmbE, T2 domain) & Ala-Glu-Ala (271.117) & $897.211(4)$ & $897.213(-2.2)$ & 532.2 & $A m b B+A m b E_{S 1819 A}{ }^{b}$ \\
\hline
\end{tabular}

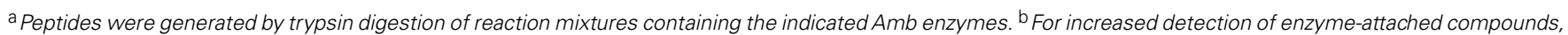

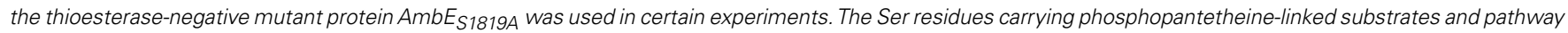
intermediates are underlined.

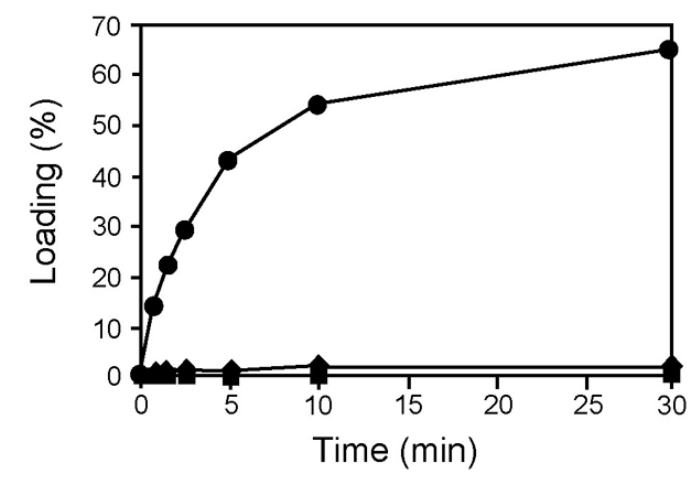

FIGURE 6 | AmbB-dependent loading of L-Ala onto the T2 domain of AmbE. AmbE (filled squares), AmbE $+\mathrm{AmbB}_{\mathrm{S} 768 \mathrm{~A}}$ (filled circles), and $A m b E_{S 1819 A}+A_{m b B}$ 5768A (filled diamonds) were incubated with ${ }^{14} \mathrm{C}$-L-Ala in an aminoacylation assay. At several time points, proteins (with bound amino acids) were precipitated and radioactivity was counted. Percentage of loading was determined using the molar ratio of bound radioactivity to the amount of AmbE/AmbE $\mathrm{S}_{1819 \mathrm{~A}}$ in the assay.

\section{ASSEMBLY OF A TRIPEPTIDE AMB PRECURSOR ON AmbE}

The identification of the substrate amino acids activated by and loaded onto AmbB and AmbE suggested that these proteins generate an L-Ala-L-Glu-L-Ala tripeptide. We speculated that the central L-Glu would be the amino acid to be converted to AMB by AmbC, $\mathrm{AmbD}$, and tailoring domains of AmbE, while the two flanking L-Ala residues may function as protective groups during these modifications. Indeed, LC-MS/MS analysis of in vitro reactions carried out with different enzyme combinations, revealed several characteristic mass shifts of the phosphopantetheinylated T1 and T2 peptides of AmbE (Table 3). A reaction mixture containing $\mathrm{AmbB}, \mathrm{AmbE}_{\mathrm{S} 1958 \mathrm{~A}}$ (a thioesterase-negative AmbE variant used to stabilize enzyme-attached AMB precursor peptides), L-Ala and L-Glu, generated not only the previously observed mass shifts of the phosphopantetheinylated amino acid substrates $[+129.04$ for Glu and +71.04 for Ala; data not shown), but also mass shifts of
+200.08 (at T1) and +271.12 (at T2; Figures S5A,B]. These masses are identical with those expected for a T1-attached Glu-Ala dipeptide and for a T2-attached Ala-Glu-Ala tripeptide, respectively. When the two oxygenases (AmbC and AmbD), their cofactors $(\alpha-$ ketoglutarate and ferrous iron), and SAM (cofactor for the MT domain of AmbE) were included in the assay, the mass shifts of these pathway intermediates were no longer detected. Instead, a new mass shift of +255.12 was identified for the T2-specific peptide (Figure 5C). This mass corresponds to that expected for an Ala-AMB-Ala tripeptide.

\section{DISCUSSION}

In this work we have demonstrated that L-Ala and L-Glu are the amino acid substrates for AMB production. The identity of these building blocks was demonstrated with classical aminoacylation assays using radiolabeled amino acid substrates and also with a MS-based approach which detected these amino acids bound via phosphopantetheinyl arms to the T domains of AmbB and AmbE (see Figure 7). Specifically, we detected L-Ala bound to the $\mathrm{T}$ domain of AmbB (Figures 3 and 5B) and to the T2 domain of AmbE (Figures 6 and S4B) while L-Glu was bound to the thiolation domain T1 of AmbE (Figures 4B and S4A). However, AmbE specifies a single adenylation domain, which was predicted to activate a polar amino acid such as L-Glu. Indeed, L-Glu was no longer loaded onto T1 when this domain was mutated (Figure 4C), most likely because the mutations had interfered with L-Glu activation. How is L-Ala bound at the AmbE's T2 site activated? As L-Ala was identified as the substrate activated by and loaded onto AmbB we hypothesized that AmbB might also be responsible for loading the T2 site of AmbE. Using an AmbB mutant unable to load its own T site we demonstrated that this was indeed the case (Figure 6).

The identification of three amino acids as the building blocks required for $\mathrm{AMB}$ generation is remarkable as $\mathrm{AMB}$ has not been found as a tripeptide but as a single non-proteinogenic amino acid with a molecular weight of $131.06 \mathrm{Da}$ (Figure 7). To further investigate this novel biosynthesis we searched for 


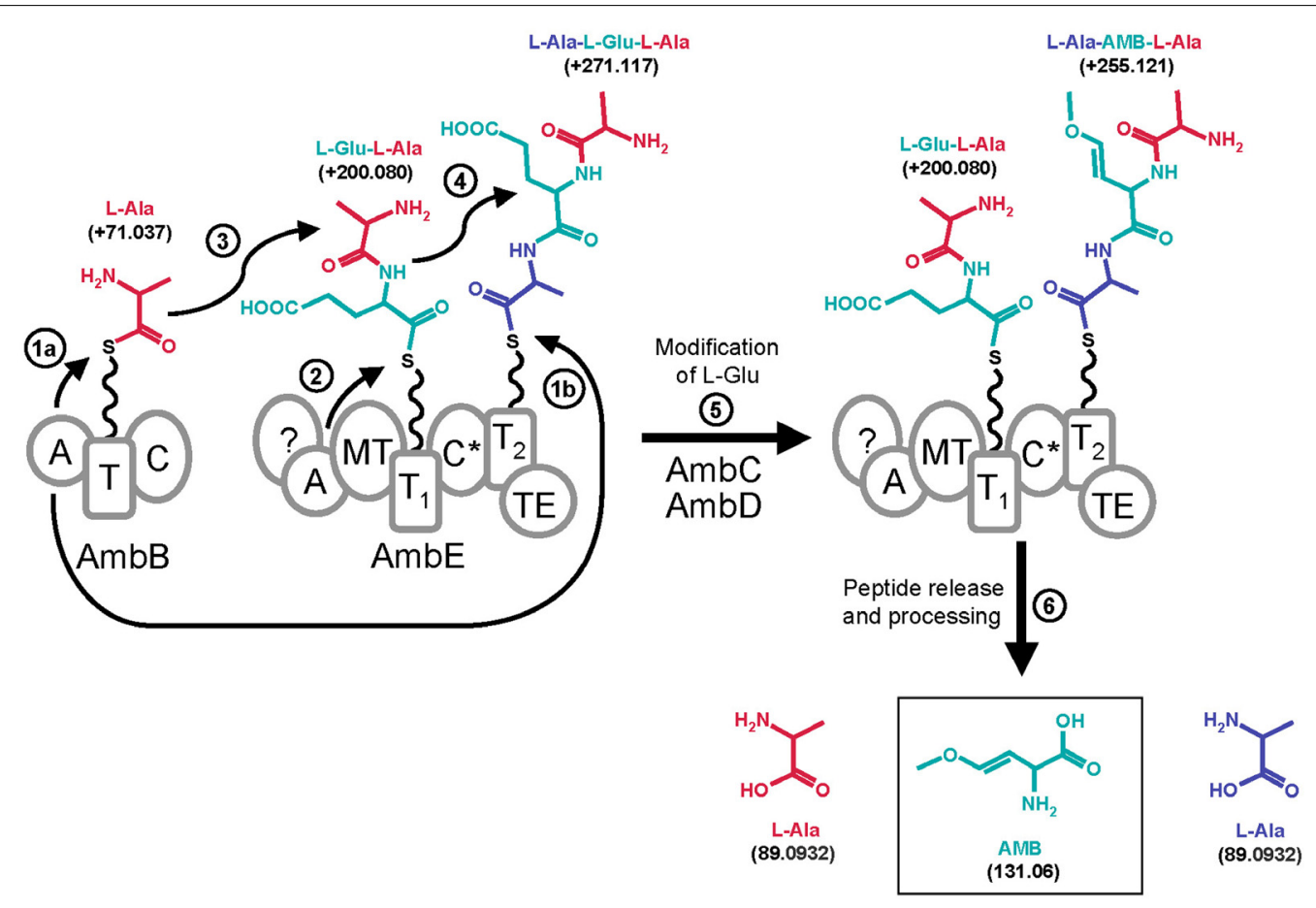

FIGURE 7 | Proposed model for AMB biosynthesis with indication of mass shifts (in Da) of tethered molecules. The A domain of AmbB activates L-Ala (residue shown in red) and loads it onto its own T domain (step 1a) and onto the T2 domain of AmbE (step 1b). The A domain of AmbE activates L-Glu (residue shown in blue) and loads it onto its T1 domain (step 2). Then, the $C$ domain of AmbB or the $C^{*}$ domain of AmbE would condense L-Ala with L-Glu onto the T1 domain of AmbE forming the L-Glu-L-Ala dipeptide (step 3). This would subsequently be condensed with L-Ala on the T2 domain of AmbE to give the tripeptide L-Ala-L-Glu-L-Ala (step 4). Modification of the central L-Glu by action of $A m b C, A m b D$, the MT domain of AmbE, and eventually by the $C^{*}$ domain and/or by the $\mathrm{N}$-term of AmbE, would give rise to the tripeptide L-Ala-AMB-L-Ala (step 5). This is believed to be the final peptide released from AmbE by action of the TE domain (step 6). Finally, the flanking L-Ala residues are removed by a processing step to yield AMB (step 6). pathway intermediates attached at the thiolation sites of AmbE and found a Glu-Ala dipeptide and an Ala-Glu-Ala tripeptide at T1 and T2, respectively (Figure S5). These compounds were no longer detected when the assay contained, in addition, the oxygenases AmbC and AmbD together with all cofactors. Instead, large amounts of an Ala-AMB-Ala tripeptide attached at T2 were detected (Figure 5C). Based on these results we propose a biosynthetic pathway for AMB production which proceeds via the generation of a tripeptide precursor. According to this model (Figure 7), the A domain of AmbB activates L-Ala which is loaded onto the protein's own $\mathrm{T}$ domain and onto the T2 domain of AmbE. The A domain of AmbE activates L-Glu, which is loaded onto the $\mathrm{T} 1$ domain. The $\mathrm{C}$ domain of AmbB then condenses L-Ala and L-Glu to form the L-Glu-L-Ala dipeptide at T1 of AmbE. This dipeptide is subsequently condensed, probably by the $\mathrm{C}^{*}$ domain, with the L-Ala residue attached at $\mathrm{T} 2$ to give the L-Ala-L-Glu-L-Ala tripetide at T2. The central amino acid, L-Glu, would then undergo a series of modifications to be converted into $A M B$ while the two flanking $L-A l a$ residues remain in place. The modifications of L-Glu would be carried out by $\mathrm{AmbC}, \mathrm{AmbD}$, and tailoring domains of AmbE (Figure 1). The order and the timing of these modifications is currently unknown and we cannot exclude at this point that some modifications of L-Glu may occur even before condensation with the two L-Ala residues, as the unmodified di- and tripeptides ( $\mathrm{L}-\mathrm{Ala}-\mathrm{L}-\mathrm{Glu}$ and
L-Ala-L-Glu-L-Ala) were observed only in the absence of AmbC and AmbD. Finally, the L-Ala-AMB-L-Ala tripeptide is released by thioester cleavage (TE domain of $\mathrm{AmbE}$ ) and processed to give $\mathrm{AMB}$ and two molecules of L-Ala.

What is the role of the two flanking L-Ala residues during biosynthesis of AMB? As previously mentioned, AMB inhibits PLP-dependent enzymes (Berkowitz et al., 2006) and as such could act as a growth inhibitor in the producer as well. We thus speculate that the two flanking L-Ala residues could not only act as protective groups during the conversion of L-Glu to AMB, but also have the additional function of preventing $\mathrm{AMB}$ toxicity during biosynthesis. It is not yet clear how processing of the Ala-AMB-Ala tripeptide occurs. We believe that the processing peptidase is encoded by $P$. aeruginosa itself as free AMB is readily detected in $P$. aeruginosa culture supernatants (Scannell et al., 1972; Lee et al., 2010). However, we cannot exclude that the AlaAMB-Ala peptide is also excreted by $P$. aeruginosa, taken up by susceptible neighbors and subjected to peptidase/amidase action to liberate the toxin. Such a "Trojan Horse" mechanism has been described previously for other bacterial toxins such as the herbicide phosphinothricin (PT), which is produced non-ribosomally by Streptomyces viridochromogens as an PT-Ala-Ala tripeptide (Metcalf and van der Donk, 2009).

Secretion of AMB (and/or its precursor tripeptide) is expected to be carried out by AmbA, a member of the LysE transporter 
family (Lee et al., 2010). However given that LysE is an amino acid transporter (Vrljic et al., 1996), there is a higher likelihood that AmbA exports AMB. We speculate that AmbA could also be crucial for resistance of the producer bacterium when free AMB re-enters the cytoplasm. As for AMB import into P. aeruginosa, it is not clear which transporter is involved, but it is interesting to note that in Staphylococcus aureus a mutation in a D-methionine transport system rendered this bacterium resistant toward AMB (our unpublished observations).

$\mathrm{AMB}$ is the first oxyvinylglycine made from L-Glu. In other cases, e.g., 4-AVG (Fernández et al., 2004), 4-FVG (Halgren et al., 2013), and rhizobitoxine (Mitchell and Coddington, 1991; Yasuta et al., 2001), the starting amino acid appears to be homoserine. Moreover, there is no evidence that these compounds are made by a thiotemplate mechanism, or processed from a precursor peptide, suggesting that there is significant diversity in the biosynthesis of oxyvinylglycines.

In summary, we have elucidated here the first steps of the AMB biosynthetic pathway. Clearly, these data confirm our previous results, which showed that the $a m b$ gene cluster is responsible for the biosynthesis of AMB (Lee et al., 2010, 2013a) and does not specify the quorum-sensing molecule IQS [2-(2-hydroxyphenyl)thiazole-4-carbaldehyde], as reported by the group of Lian-Hui Zhang (Lee et al., 2013b). The chemical structure of IQS indicates that this compound may be assembled from salicylate and cysteine. However, neither of the two peptide synthetases encoded by the $a m b$ gene cluster present adenylation domains with a specificity for these substrates and the biochemical assays performed in this work show that AmbB is loaded with alanine while AmbE is loaded with glutamate and alanine. It is thus highly implausible that IQS is specified by the $a m b$ gene cluster. Unfortunately, the authors of the IQS publication did not verify which molecule was produced in an E. coli strain overexpressing $a m b B C D E$. Moreover, their biotest used to measure AMB production was not performed as should be (Lee et al., 2010) which caused a misinterpretation of the results. As proposed recently by Ye et al. (2014), IQS - which is actually aeruginaldehyde seems instead to be a byproduct produced from salicylate coupled to the first moiety of cysteine during biosynthesis of the enantiomeric siderophores pyochelin and enantiopyochelin in $P$. aeruginosa and $P$. fluorescens, respectively (reviewed by Youard et al., 2011).

Many questions concerning the biosynthesis and transport of AMB remain open. It will be fascinating to dissect the function of the tailoring enzymes, to determine the order in which the modifications of L-Glu occur, to identify the processing enzyme, and to investigate the role of AmbA in AMB export and immunity.

\section{ACKNOWLEDGMENTS}

The authors would like to thank William Wuest and Dieter Haas for helpful discussions. This work was supported by a Short Term EMBO Fellowship to XL and a UNIL Master's grant to NRM.

\section{SUPPLEMENTARY MATERIAL}

The Supplementary Material for this article can be found online at: http://www.frontiersin.org/journal/10.3389/fmicb.2015.00170/ abstract

\section{REFERENCES}

Bachmann, B. O., and Ravel, J. (2009). Methods for in silico prediction of microbial secondary metabolic pathways from DNA sequence data. Methods Enzymol. 458, 181-217. doi: 10.1016/S0076-6879(09)04808-3

Banowetz, G. M., Azevedo, M. D., Armstrong, D. J., Halgren, A. B., and Mills, D. I. (2008). Germination arrest factor (GAF): biological properties of a novel, naturally-occurring herbicide produced by selected isolates of rhizosphere bacteria. Biol. Control 46, 380-390. doi: 10.1016/j.biocontrol.2008. 04.016

Berkowitz, D., Charrette, B. D., Karukurichi, K. R., and McFadden, J. M. (2006). $\alpha$-Vinylic amino acids: occurrence, asymmetric synthesis, and biochemical mechanisms. Tetrahedron Asymmetry 17, 869-882. doi: 10.1016/j.tetasy.2006. 02.026

Boc, A., Diallo, A. B., and Makarenkov, V. (2012). T-REX: a web server for inferring, validating and visualizing phylogenetic trees and networks. Nucleic Acids Res. 40, W573-W579. doi: 10.1093/nar/gks485

Cornell, N. W., Zuurendonk, P. F., Kerich, M. J., and Straight, C. B. (1984). Selective inhibition of alanine aminotransferase and aspartate aminotransferase in rat hepatocytes. J. Biochem. 220, 707-716.

Dashman, T., and Kamm, J. J. (1979). Inhibition of $\delta$-aminolevulinic acid synthetase and $\delta$-aminolevulinic acid dehydrase by L-2-amino-4-methoxy-trans-3-butenoic acid in the rat. Life Sci. 24, 185-192. doi: 10.1016/0024-3205(79)90129-2

Dorrestein, P., Blackhall, J., Straight, P., Fischbach, M., Garneau-Tsodikova, S., Edwards, D., etal. (2006). Activity screening of carrier domains within nonribosomal peptide synthetases using complex substrate mixtures and large molecule mass spectrometry. Biochemistry 45, 1537-1546. doi: 10.1021/bi0 $52333 \mathrm{k}$

Farinha, M. A., and Kropinski, A. M. (1990). High efficiency electroporation of Pseudomonas aeruginosa using frozen cell suspensions. FEMS Microbiol. Lett. 58, 221-225. doi: 10.1016/S0378-1097(05)80043-6

Fernández, M., Cuadrado, Y., Aparicio, J. F., and Martín, J. F. (2004). Role of homoserine and threonine pathway intermediates as precursors for the biosynthesis of aminoethoxyvinylglycine in Streptomyces sp. NRRL 5331. Microbiology 50, 1467-1474. doi: 10.1099/mic.0.26851-0

Halgren, A., Maselko, M., Azevedo, M., Mills, D., Armstrong, D., and Banowetz, G. (2013). Genetics of germination-arrest factor (GAF) production by Pseudomonas fluorescens WH6: identification of a gene cluster essential for GAF biosynthesis. Microbiology 159, 36-45. doi: 10.1099/mic.0.062166-0

Hausinger, R. (2004). Fe(II)/ $\alpha$-ketoglutarate-dependent hydroxylases and related enzymes. Crit. Rev. Biochem. Mol. Biol. 39, 21-68. doi: 10.1080/10409230490440541

Hirata, H., Kato, A., Nakatani, S., Aiba, T., Oohashi, Y., and Goto, M. (1993). Antibiotics WAP-5044C and WAP-5044A, WAP-5044C derivative, their manufactures with Streptomyces, and fungicides containing them. JP Patent 05 105657.

Hollenhorst, M., Bumpus, S., Matthews, M., Bollinger, J. Jr., Kelleher, N., and Walsh, C. (2010). The nonribosomal peptide synthetase enzyme DdaD tethers $\mathrm{N} \beta$-Fumaramoyl-1-2,3-diaminopropionate for $\mathrm{Fe}(\mathrm{II}) / \alpha$-ketoglutarate-dependent epoxidation by DdaC during dapdiamide antibiotic biosynthesis. J. Am. Chem. Soc. 132, 15773-15781. doi: 10.1021/ja1072367

Lee, X., Azevedo, M., Armstrong, D., Banowetz, G., and Reimmann, C. (2013a). The Pseudomonas aeruginosa antimetabolite L-2-amino-4-methoxy-trans-3-butenoic acid inhibits growth of Erwinia amylovora and acts as a seed germinationarrest factor. Environ. Microbiol. Rep. 5, 83-89. doi: 10.1111/j.1758-2229.2012. 00395.x

Lee, J., Wu, J., Deng, Y., Wang, J., Wang, C., Wang, J., et al. (2013b). A cell-cell communication signal integrates quorum sensing and stress response. Nat. Chem. Biol. 9, 339-343. doi: 10.1038/nchembio.1225

Lee, X., Fox, A., Sufrin, J., Henry, H., Majcherczyk, P., Haas, D., et al. (2010). Identification of the biosynthetic gene cluster for the Pseudomonas aeruginosa antimetabolite L-2-Amino-4-methoxy-trans-3-butenoic acid. J. Bacteriol. 192, 4251-4255. doi: 10.1128/JB.00492-10

Lee, X., Reimmann, C., Greub, G., Sufrin, J., and Croxatto, A. (2012). The Pseudomonas aeruginosa toxin L-2-Amino-4-methoxy-trans-3-butenoic acid inhibits growth and induces encystment in Acanthamoeba castellanii. Microbes Infect. 14, 268-272. doi: 10.1016/j.micinf.2011.10.004

Lyczak, J. B., Cannon, C. L., and Pier, G. B. (2002). Lung infections associated with cystic fibrosis. Clin. Microbiol. Rev. 15, 194-222. doi: 10.1128/CMR.15.2.194222.2002 
Marahiel, M. A., Stachelhaus, T., and Mootz, H. D. (1997). Modular peptide synthetases involved in nonribosomal peptide synthesis. Chem. Rev. 97, 2651-2674. doi: $10.1021 / \mathrm{cr} 960029 \mathrm{e}$

Marchler-Bauer, A., and Bryant, S. H. (2004). CD-Search: protein domain annotations on the fly. Nucleic Acids Res. 32, 327-331. doi: 10.1093/nar/gkh454

Matoo, A. K., Anderson, J. D., Chalutz, E., and Lieberman, M. (1979). Influence of enol ether amino acids, inhibitors of ethylene biosynthesis, on aminoacyl transfer RNA synthetases and protein synthesis. Plant Physiol. 64, 289-292. doi: 10.1104/pp.64.2.289

McPhail, K. L., Armstrong, D. J., Azevedo, M. D., Banowetz, G. M., and Mills, D. I. (2010). 4-Formylaminooxyvinylglycine, an herbicidal germination-arrest factor from Pseudomonas rhizosphere bacteria. J. Nat. Prod. 73, 1853-1857. doi: $10.1021 / \mathrm{np} 1004856$

Meier, J., Patel, A., Niessen, S., Meehan, M., Kersten, R., Yang, J., et al. (2011). Practical 4'-phosphopantetheine active site discovery from proteomic samples. J. Proteome Res. 10, 320-329. doi: 10.1021/pr100953b

Meluzzi, D., Zheng, W., Hensler, M., Nizet, V., and Dorrestein, P. (2008). Top-down mass spectrometry on low-resolution instruments: characterization of phosphopantetheinylated carrier domains in polyketide and nonribosomal biosynthetic pathways. Bioorg. Med. Chem. Lett. 18, 3107-3111. doi: 10.1016/j.bmcl.2007.10.104

Metcalf, W. W., and van der Donk, W. A. (2009). Biosynthesis of phosphonic and phosphinic acid natural products. Annu. Rev. Biochem. 78, 65-94. doi: 10.1146/annurev.biochem.78.091707.100215

Miles, E. W. (1975). A new type of pyridoxal-p enzyme catalyzed reaction: the conversion of $\beta, \gamma$-unsaturated amino acids to saturated $\alpha$-keto acids by tryptophan synthase. Biochem. Biophys. Res. Commun. 66, 94-102. doi: 10.1016/S0006-291X(75)80299-3

Mitchell, R. E., and Coddington, J. M. (1991). Biosynthetic pathway to rhizobitoxine in Pseudomonas andropogonis. Phytochemistry 30, 1809-1814. doi: 10.1016/00319422(91)85018-U

Mitchell, R. E., Frey, E. J., and Benn, M. H. (1986). Rhizobitoxin and Lthreohydroxythreonine production by the plant pathogen Pseudomonas andropogonis. Phytochemistry 25, 2711-2715.

Owens, L. D., Thompson, J. F., Pitcher, R. G., and Williams, T. (1972). Structure of rhizobitoxine, an antimetabolic enolether amino-acid from Rhizobium japonicum. J. Chem. Soc. Chem. Commun. (Camb.) 12, 714. doi: $10.1039 / \mathrm{c} 39720000714$

Pruess, D. L., Scannell, J. P., Kellett, M., Ax, H. A., Janecek, J., Williams, T. H., et al. (1974). Antimetabolites produced by microorganisms. X. L-2Amino-4-(2-aminoethoxy)-trans-3-butenoic acid. J. Antibiot. 27, 229-233. doi: 10.7164/antibiotics.27.229

Rando, R. R. (1974). $\beta, \gamma$-Unsaturated amino acids as irreversible enzyme inhibitors. Nature 250, 586-587. doi: 10.1038/250586a0

Rando, R. R., Relyea, N., and Cheng, L. (1976). Mechanism of the irreversible inhibition of aspartate aminotransferase by the bacterial toxin L-2-Amino-4-methoxy-trans-3-butenoic acid. J. Biol. Chem. 251, 3306-3312.

Sahm, U., Knobloch, G., and Wagner, F. (1973). Isolation and characterization of the methionine antagonist L-2-amino-4-methoxy-trans-3-butenoic acid from Pseudomonas aeruginosa grown on n-paraffin. J. Antibiot. 26, 389-390. doi: 10.7164/antibiotics.26.389

Saitou, N., and Nei, M. (1987). The neighbor-joining method: a new method for reconstructing phylogenetic trees. Mol. Biol. Evol. 4, 406-425.

Sambrook, J., and Russell, D. (2001). Molecular Cloning: A Laboratory Manual, 3rd Edn. Cold Spring Harbor, NY: Cold Spring Harbor Laboratory Press.

Scannell, J. P., Pruess, D. L., Demny, T. C., Sello, L. H., Williams, T., and Stempel, A. (1972). Antimetabolites produced by microorganisms. V. L-2-Amino-4-methoxytrans-3-butenoic acid. J. Antibiot. 25, 122-127. doi: 10.7164/antibiotics.25.122

Sievers, F., Wilm, A., Dineen, D., Gibson, T. J., Karplus, K., Li, W., et al. (2011). Fast, scalable generation of high-quality protein multiple sequence alignments using Clustal Omega. Mol. Syst. Biol. 7, 539. doi: 10.1038/msb.2011.75

Smith, S. B., and Freeland, R. A. (1981). Functional inhibition of cytosolic and mitochondrial aspartate aminotransferase by L-2-amino-4-methoxy-trans-3-butanoic acid in isolated rat hepatocytes and mitochondria. Arch. Biochem. Biophys. 209, 335-341. doi: 10.1016/0003-9861(81)90289-7

Stachelhaus, T., Mootz, H. D., Bergendahl, V., and Marahiel, M. A. (1998). Peptide bond formation in nonribosomal peptide biosynthesis. Catalytic role of the condensation domain. J. Biol. Chem. 273, 22773-22781. doi: 10.1074/jbc.273.35.22773

Stanisich, V. A., and Holloway, B. W. (1972). A mutant sex factor of Pseudomonas aeruginosa. Genet. Res. 19, 91-108. doi: 10.1017/S0016672300014294

Stein, T., Vater, J., Kruft, V., Otto, A., Wittmann-Liebold, B., Franke, P., et al. (1996). The multiple carrier model of nonribosomal peptide biosynthesis at modular multienzymatic templates. J. Biol. Chem. 271, 15428-15435. doi: 10.1074/jbc.271.26.15428

Tatum, E. L., and Lederberg, J. (1947). Gene recombination in the bacterium. J. Bacteriol. 53, 673-684.

Thompson, J. D., Higgins, D. G., and Gibson, T. J. (1994). CLUSTAL W: improving the sensitivity of progressive multiple sequence alignment through sequence weighting, position-specific gap penalties and weight matrix choice. Nucleic Acids Res. 22, 4673-4680. doi: 10.1093/nar/22.22.4673

Tillet, D., Dittmann, E., Erhard, M., von Döhren, H., and Neilan, B. A. (2000). Structural orgnization of microcystin biosynthesis in Mycrocystis aeruginosa PCC7806: an integrated peptide-polyketide synthetase system. Chem. Biol. 216, 255-265.

Tisdale, M. J. (1981). The effect of L-2-amino-4-methoxy-trans-3-butenoic acid on serine hydroxymethyl transferase. Chem. Biol. Interact. 34, 75-83. doi: 10.1016/0009-2797(81)90092-2

Voisard, C., Rella, M., and Haas, D. (1988). Conjugative transfer of plasmid RP1 to soil isolates of Pseudomonas fluorescens is facilitated by certain large RP1 deletions. FEMS Microbiol. Lett. 55, 9-13. doi: 10.1111/j.1574-6968.1988.tb02790.x

Vrljic, M., Sahm, H., and Eggeling, L. (1996). A new type of transporter with a new type of cellular function: L-lysine export from Corynebacterium glutamicum. Mol. Microbiol. 22, 815-826. doi: 10.1046/j.1365-2958.1996.01527.x

Winsor, G. L., Lam, D. K., Fleming, L., Lo, R., Whiteside, M. D., Yu, N. Y., et al. (2011). Pseudomonas Genome Database: improved comparative analysis and population genomics capability for Pseudomonas genomes. Nucleic Acids Res. 39, D596-D600. doi: 10.1093/nar/gkq869

Yasuta, T., Okazaki, S., Mitsui, H., Yuhashi, K., Ezura, H., and Minamisawa, K. (2001). DNA sequence and mutational analysis of rhizobotoxin biosynthesis genes in Bradyrhizobium elkanii. Appl. Environ. Microbiol. 67, 4999-5009. doi: 10.1128/AEM.67.11.4999-5009.2001

Ye, L., Cornelis, P., Guillemyn, K., Ballet, S., Christophersen, C., and Hammerich, O. (2014). Structure revision of N-Mercapto-4-formylcarbostyril produced by Pseudomonas fluorescens G308 to 2-(2-Hydroxyphenyl)thiazole-4-carbaldehyde [aeruginaldehyde]. Nat. Prod. Commun. 9, 789-794.

Ye, R. W., Haas, D., Ka, J. O., Krishnapillai, V., Zimmermann, A., Baird, C., et al. (1995). Anaerobic activation of the entire denitrification pathway in Pseudomonas aeruginosa requires Anr, an analog of Fnr. J. Bacteriol. 177, 3606-3609.

Yin, J., Lin, A. J., Golan, D. E., and Walsh, C. T. (2006). Site-specific protein labeling by Sfp phosphopantetheinyl transferase. Nat. Protoc. 1, 280-285. doi: 10.1038/nprot.2006.43

Youard, Z. A., Wenner, N., and Reimmann, C. (2011). Iron acquisition with the natural siderophore enantiomers pyochelin and enantio-pyochelin in Pseudomonas species. Biometals 24, 513-522. doi: 10.1007/s10534-010-9399-9

Conflict of Interest Statement: The authors declare that the research was conducted in the absence of any commercial or financial relationships that could be construed as a potential conflict of interest.

Received: 19 December 2014; paper pending published: 18 January 2015; accepted: 13 February 2015; published online: 12 March 2015.

Citation: Rojas Murcia N, Lee X, Waridel P, Maspoli A, Imker HJ, Chai T, Walsh CT and Reimmann C (2015) The Pseudomonas aeruginosa antimetabolite L-2-amino4-methoxy-trans-3-butenoic acid $(A M B)$ is made from glutamate and two alanine residues via a thiotemplate-linked tripeptide precursor. Front. Microbiol. 6:170. doi: 10.3389/fmicb.2015.00170

This article was submitted to Antimicrobials, Resistance and Chemotherapy, a section of the journal Frontiers in Microbiology.

Copyright (c) 2015 Rojas Murcia, Lee, Waridel, Maspoli, Imker, Chai, Walsh and Reimmann. This is an open-access article distributed under the terms of the Creative Commons Attribution License (CC BY). The use, distribution or reproduction in other forums is permitted, provided the original author(s) or licensor are credited and that the original publication in this journal is cited, in accordance with accepted academic practice. No use, distribution or reproduction is permitted which does not comply with these terms. 